SUPPORTING INFORMATION

\title{
Biosynthesis of the Fusarium Mycotoxin (-)-Sambutoxin
}

Eun Bin $\mathrm{Go}^{1}$, Lee Joon $\mathrm{Kim}^{1}$, Hosea M. Nelson ${ }^{1,3 *}$, Masao Ohashi ${ }^{2 *}$, and Yi Tang ${ }^{1,2 *}$

${ }^{1}$ Department of Chemistry and Biochemistry, University of California, Los Angeles, CA 90095, USA.

${ }^{2}$ Department of Chemical and Biomolecular Engineering, University of California, Los Angeles, CA 90095, USA.

${ }^{3}$ Department of Chemistry, California Institute of Technology, Pasadena, CA 91125, USA. 
Table of Contents

1. Materials and Methods

1.1. Growth media, buffers and solutions used in this study

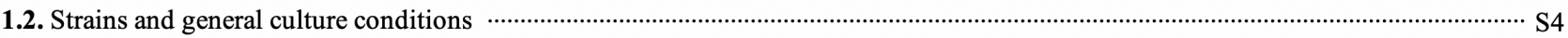

1.3. General DNA manipulation methods

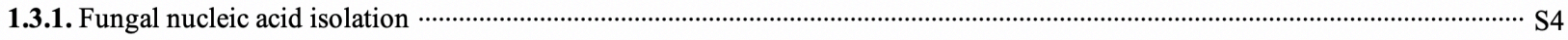

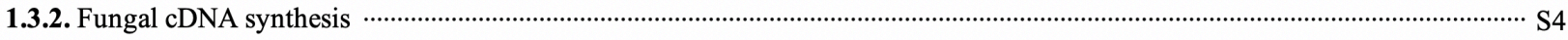

1.3.3. Construction of plasmids for heterologous expression in A. nidulans

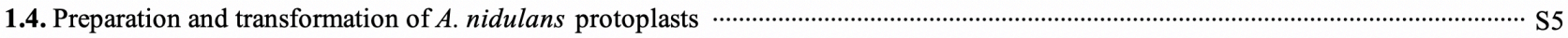

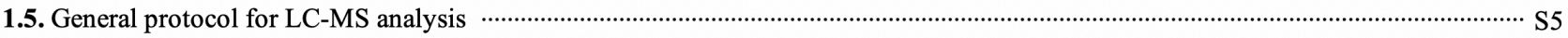

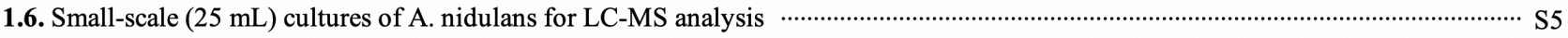

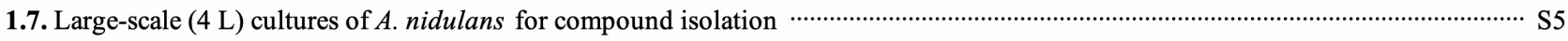

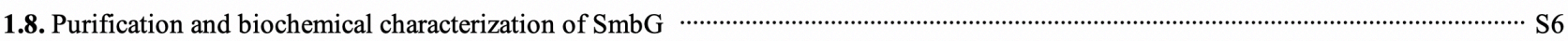

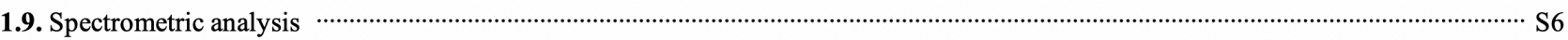

1.10. Electron diffraction data collection, refinement and statistics for 13

2. Supplementary Tables

Table S1. Deduced functions of open reading frames in the $\mathrm{smb}$ cluster from $F$. commune …….......................................................... S7

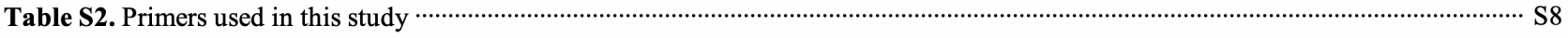

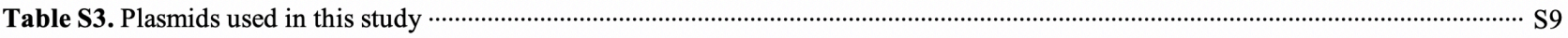

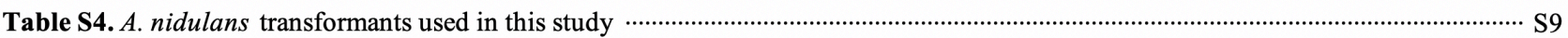

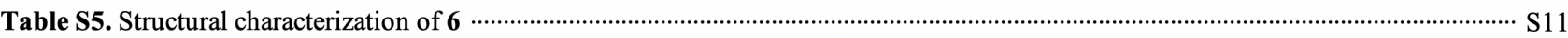

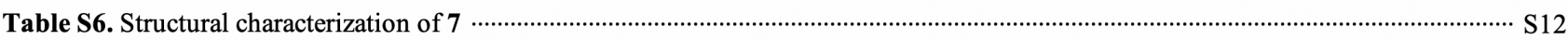

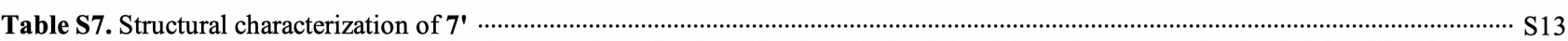

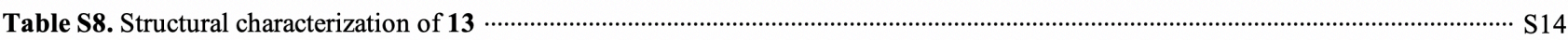

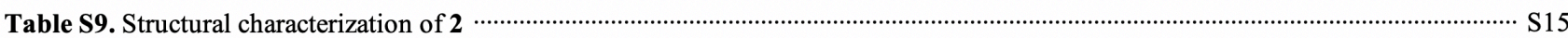

3. Supplementary Figures

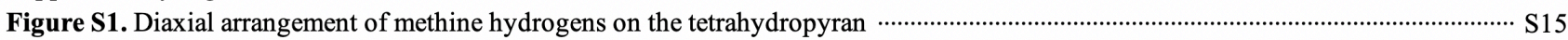

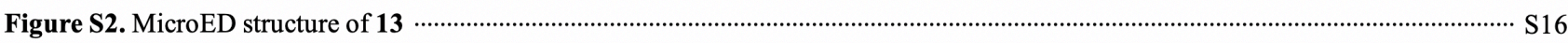

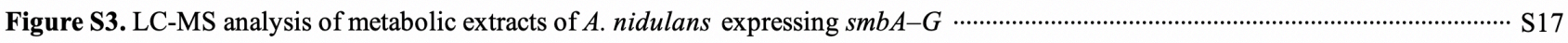

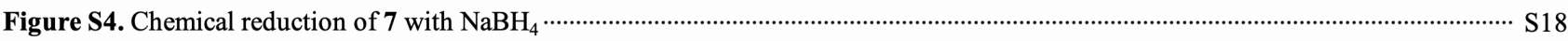

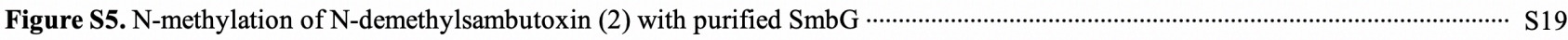

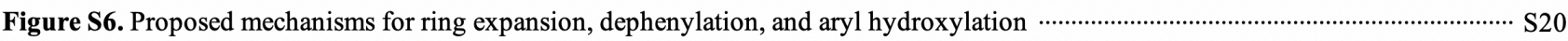

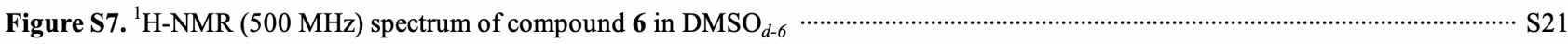

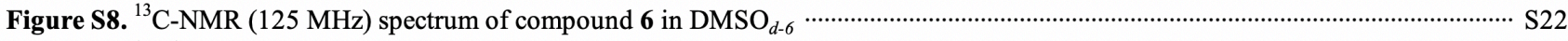

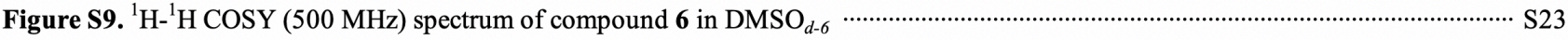

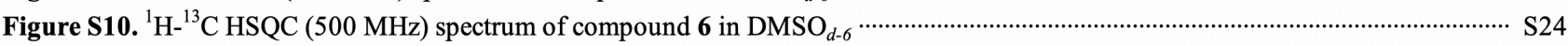

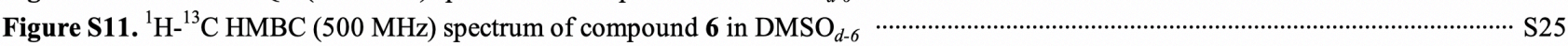

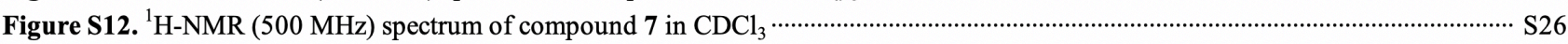

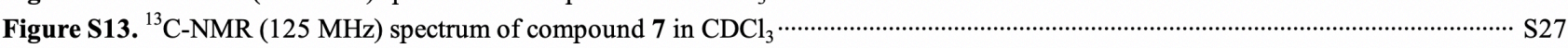

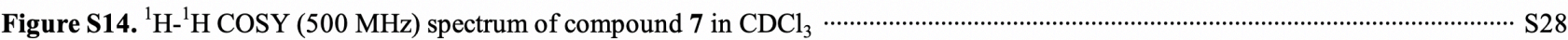

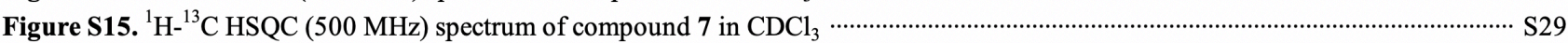

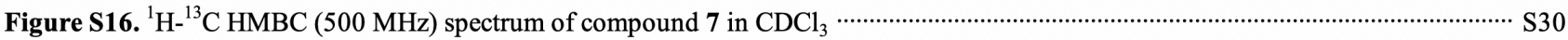

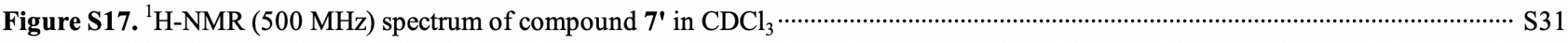

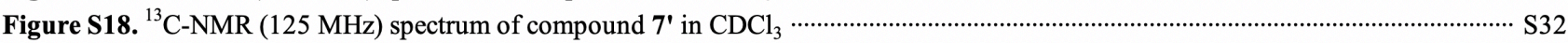

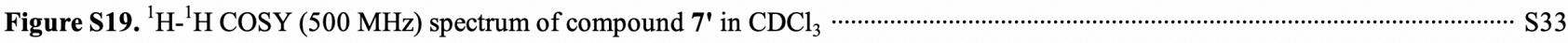

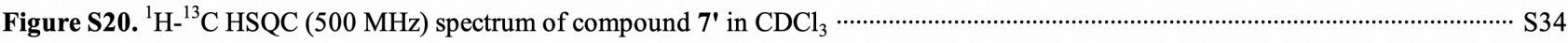

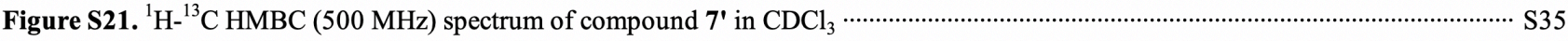

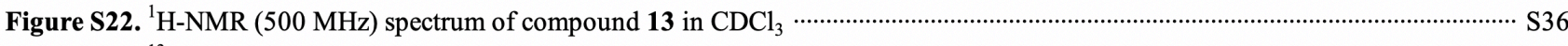

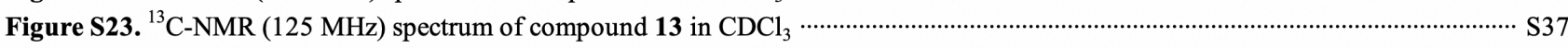

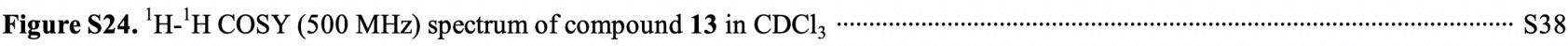

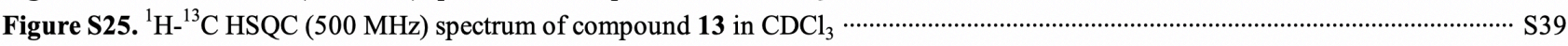

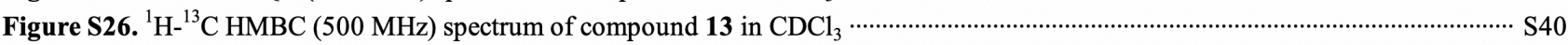

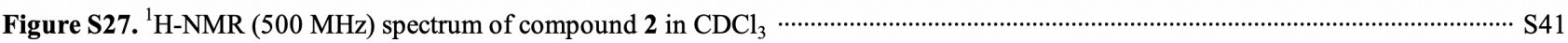

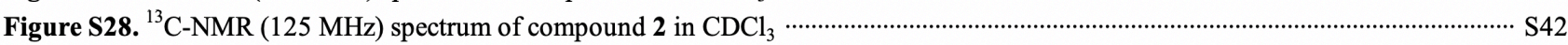

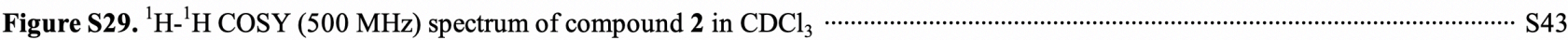

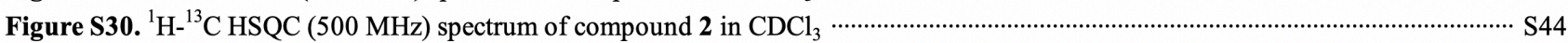

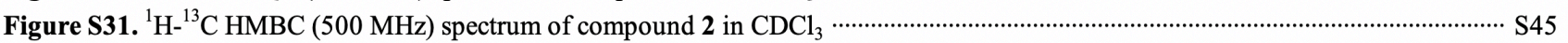




\section{Materials and Methods}

1.1. Growth media, buffers and solutions used in this study

\begin{tabular}{|c|c|}
\hline Nitrate salts & $120 \mathrm{~g} \mathrm{NaNO}_{3}, 10.4 \mathrm{~g} \mathrm{KCl}, 10.4 \mathrm{~g} \mathrm{MgSO}_{4} \cdot 7 \mathrm{H}_{2} \mathrm{O}, 30.4 \mathrm{~g} \mathrm{KH}_{2} \mathrm{PO}_{4}$ in $1 \mathrm{~L}$ deionized $\mathrm{H}_{2} \mathrm{O}$ \\
\hline Trace elements & $\begin{array}{l}2.20 \mathrm{~g} \mathrm{ZnSO}_{4} \cdot 7 \mathrm{H}_{2} \mathrm{O}, 1.10 \mathrm{~g} \mathrm{H}_{3} \mathrm{BO}_{3}, 0.50 \mathrm{~g} \mathrm{MnCl}_{2} \cdot 4 \mathrm{H}_{2} \mathrm{O}, 0.16 \mathrm{~g} \mathrm{FeSO}_{4} \cdot 7 \mathrm{H}_{2} \mathrm{O}, 0.16 \mathrm{~g} \\
\mathrm{CoCl}_{2} \cdot 5 \mathrm{H}_{2} \mathrm{O}, 0.16 \mathrm{~g} \mathrm{CuSO}_{4} \cdot 5 \mathrm{H}_{2} \mathrm{O}, 0.11 \mathrm{~g}\left(\mathrm{NH}_{4}\right)_{6} \mathrm{Mo}_{7} \mathrm{O}_{24} \cdot 4 \mathrm{H}_{2} \mathrm{O} \text { in } 100 \mathrm{~mL} \text { deionized } \mathrm{H}_{2} \mathrm{O} \text {; } \\
\text { pH } 6.5\end{array}$ \\
\hline Liquid CD & $0.1 \%$ glucose, $5 \% \mathrm{v} / \mathrm{v}$ nitrate salts, $0.1 \% \mathrm{v} / \mathrm{v}$ trace elements \\
\hline CD agar & Liquid CD with $2 \%$ agar \\
\hline YPD media & $1 \%$ yeast extract, $2 \%$ peptone, $2 \%$ glucose \\
\hline CD-ST soft agar & $2 \%$ starch, $2 \%$ casamino acids, $5 \% \mathrm{v} / \mathrm{v}$ nitrate salts, $0.1 \% \mathrm{v} / \mathrm{v}$ trace elements, $1 \%$ agar \\
\hline Osmotic medium & 1.2 $\mathrm{M} \mathrm{MgSO}_{4}, 10 \mathrm{mM}$ sodium phosphate; $\mathrm{pH} 5.8$ \\
\hline Trapping buffer & $0.6 \mathrm{M}$ sorbitol, $0.1 \mathrm{M}$ Tris- $\mathrm{HCl} ; \mathrm{pH} 7.0$ \\
\hline STC buffer & 1.2 M sorbitol, $10 \mathrm{mM} \mathrm{CaCl} 2,10 \mathrm{mM}$ Tris-HCl; $\mathrm{pH} 7.5$ \\
\hline TE buffer & 1 mM EDTA, 10 mM Tris-HCL; pH 7.8 \\
\hline
\end{tabular}

\subsection{Strains and general culture conditions}

Aspergillus nidulans A1145 $\triangle \mathrm{EM} \Delta \mathrm{ST}$ was grown on CD agar supplemented with $10 \mathrm{mM}$ uridine, $5 \mathrm{mM}$ uracil, $0.5 \mu \mathrm{g} / \mathrm{mL}$ pyridoxine $\cdot \mathrm{HCl}$ and $2.5 \mu \mathrm{g} / \mathrm{mL}$ riboflavin for sporulation or on CD-ST soft agar for heterologous expression of biosynthetic genes, compound production, and RNA isolation. All Escherichia coli strains were cultured in liquid LB media at $37^{\circ} \mathrm{C}-$ strain DH5 $\alpha$ was used for plasmid propagation and BL21 (DE3) for protein expression. Yeast was cultured in YPD media.

\subsection{General DNA manipulation techniques}

DNA restriction enzymes were used as recommended by the manufacturer (New England Biolabs, NEB). PCR was performed with Phusion or Q5 DNA polymerase (NEB). E. coli DH5 $\alpha$ cells were used for cloning, following standard recombinant DNA techniques. The primers used in this study are listed in Table S2.

\subsubsection{Fungal nucleic acid isolation}

Fungal gDNA was isolated by beating the cell body with $50 \mu \mathrm{L} 0.5 \mathrm{~mm}$ Zirconia beads in $1 \mathrm{~mL} \mathrm{1:1} \mathrm{vol.} \mathrm{mixture} \mathrm{of} \mathrm{LETS}$ buffer $\left(0.1 \mathrm{M} \mathrm{LiCl}, 0.01 \mathrm{M} \mathrm{Na}_{2} \mathrm{EDTA}, 0.01 \mathrm{M}\right.$ Tris-HCl at $\left.\mathrm{pH} 7.4,0.2 \% \mathrm{SDS}\right)$ and phenol: $\mathrm{CHCl}_{3}$ solution (10 min) to rupture the cells. The organic and aqueous layers were separated by centrifugation, and the aqueous layer was added to 1 $\mathrm{mL} i$ - $\mathrm{PrOH}$ to precipitate the gDNA. The gDNA was pelleted, washed with $70 \% \mathrm{EtOH} / \mathrm{H}_{2} \mathrm{O}$, resuspended in $\mathrm{H}_{2} \mathrm{O}$, purified on the DNA Clean \& Concentrator ${ }^{\mathrm{TM}}-5$ (Zymo Inc. USA) and stored in TE buffer at $4{ }^{\circ} \mathrm{C}$.

Fungal RNA was isolated using the RiboPure ${ }^{\mathrm{TM}}$-Yeast Kit (Invitrogen ${ }^{\mathrm{TM}}$ AM1926), digested with DNase I (NEB M0303L) $\left(37^{\circ} \mathrm{C}, 3\right.$ hours), purified on the DNA Clean \& Concentrator ${ }^{\mathrm{TM}}-5$ and stored in TE buffer at $-20{ }^{\circ} \mathrm{C}$.

\subsubsection{Fungal cDNA library synthesis}

SuperScript III First-Strand Synthesis System (Invitrogen ${ }^{\mathrm{TM}}$ 18080051) was used to synthesize the cDNA library from fungal RNA via reverse transcription with oligo-dT primers according to the manufacturer's protocol.

\subsubsection{Construction of plasmids for heterologous expression in $\boldsymbol{A}$. nidulans}

Plasmids for heterologous expression in A. nidulans were constructed by in vivo homologous recombination in the yeast strain Saccharomyces cerevisiae BJ5464-NpgA (MATa ura3-52 his3-4200 leu2-41 trp1 pep4::HIS3 prb1 $\triangle 1.6 R$ can1 GAL). For each plasmid, gene inserts were amplified by PCR and co-transformed into yeast with the appropriate double-digested pYTU, pYTR, or pYTP vector. Assembled plasmids were isolated from yeast using the Zymoprep ${ }^{\mathrm{TM}}$ Yeast Plasmid Miniprep I Kit (Zymo Inc. USA) and transformed into E. coli DH5 $\alpha$ cells by electroporation. The sequences of plasmids were verified by sequencing (Laragen Inc.). The plasmids used in this study are listed Table $\mathbf{S 3}$. 


\subsection{Preparation and transformation of $\boldsymbol{A}$. nidulans protoplasts}

Spores of $A$. nidulans A1145 $\triangle \mathrm{ST} \Delta \mathrm{EM}^{1}$ were inoculated into $50 \mathrm{~mL}$ liquid $\mathrm{CD}$ supplemented with $10 \mathrm{mM}$ uridine, $5 \mathrm{mM}$ uracil, $0.5 \mu \mathrm{g} / \mathrm{mL}$ pyridoxine $\cdot \mathrm{HCl}$ and $2.5 \mu \mathrm{g} / \mathrm{mL}$ riboflavin in a $250-\mathrm{mL}$ flask and germinated $\left(30{ }^{\circ} \mathrm{C}, 250 \mathrm{rpm}, 16 \mathrm{~h}\right)$. Mycelia were harvested by centrifugation $\left(24^{\circ} \mathrm{C}, 4,300 \mathrm{rpm}, 10 \mathrm{~min}\right)$, washed with $10 \mathrm{~mL}$ osmotic medium, re-suspended in $10 \mathrm{~mL}$ osmotic medium containing $30 \mathrm{mg}$ lysing enzymes from Trichoderma (MilliporeSigma) and $20 \mathrm{mg}$ Yatalase (Takara) in a $125-\mathrm{mL}$ flask and digested overnight $\left(30^{\circ} \mathrm{C}, 80 \mathrm{rpm}, 15 \mathrm{~h}\right)$. The digest mixture was transferred to a $15-\mathrm{mL}$ conical tube and gently overlaid with $5 \mathrm{~mL}$ trapping buffer, and protoplasts were collected from the interface of the buffer layers after centrifugation $\left(4^{\circ} \mathrm{C}, 4,300 \mathrm{rpm}, 15 \mathrm{~min}\right)$. The protoplasts were transferred to a new $15-\mathrm{mL}$ conical tube, washed with $10 \mathrm{~mL}$ STC buffer, resuspended in $2 \mathrm{~mL}$ STC buffer and stored as $40 \mu \mathrm{L}$ aliquots at $-80^{\circ} \mathrm{C}$. The protoplasts remained competent for transformation for more than 7 months.

For each transformation, $1 \mu \mathrm{L}$ of each plasmid was added to a freshly thawed $40-\mu \mathrm{L}$ aliquot of $A$. nidulans protoplasts and incubated on ice for 45 minutes. $600 \mu \mathrm{L}$ PEG solution was added to the protoplast/plasmid mixture and mixed by gentle shaking to form a homogenous mixture, which was spread on the regeneration medium (CD agar with 1.2 M sorbitol) and incubated at $37^{\circ} \mathrm{C}$ for 2-3 days until colonies of transformants appeared. The transformants were transferred to CD agar and stored at $28^{\circ} \mathrm{C}$. The $A$. nidulans transformants prepared in this study are listed in Table $\mathbf{S 4}$.

\subsection{General protocol for LC-MS analysis}

Samples were analyzed on the Shimadzu 2020 EV LC-MS with a reversed-phase C18 column (Phenomenex Kinetex, 1.7 $\mu \mathrm{m}, 100 \AA, 2.1 \times 100 \mathrm{~mm}$ ) with positive- and negative-mode electrospray ionization. A linear gradient of 5-95\% MeCN/ $\mathrm{H}_{2} \mathrm{O}$ in 15 minutes followed by $95 \% \mathrm{MeCN} / \mathrm{H}_{2} \mathrm{O}$ for 3 minutes with a flow rate of $0.3 \mathrm{~mL} / \mathrm{min}$. was applied for each sample. The $\mathrm{MeCN}$ and $\mathrm{H}_{2} \mathrm{O}$ were supplemented with $0.1 \% \mathrm{v} / \mathrm{v}$ formic acid.

\subsection{Small-scale ( $25 \mathrm{~mL})$ cultures of $\boldsymbol{A}$. nidulans transformants for LC-MS analysis}

A. nidulans transformants were grown on $25 \mathrm{~mL} \mathrm{CD-ST}$ soft agar $\left(28{ }^{\circ} \mathrm{C}, 3-4\right.$ days $)$ and extracted overnight with $25 \mathrm{~mL}$ EtOAc. For each LC-MS analysis, $750 \mu \mathrm{L}$ of the EtOAc extract was washed with $750 \mu \mathrm{L} \mathrm{H}_{2} \mathrm{O}$, and the organic layer was dried and re-dissolved in $50 \mu \mathrm{L} \mathrm{MeOH}$, of which $10 \mu \mathrm{L}$ was used for LC-MS analysis.

\subsection{Large-scale (4 L) cultures of $\boldsymbol{A}$. nidulans transformants for compound purification}

For isolation of 6, 7, 9 and 3, each A. nidulans transformant (Table S4) was grown on $4 \mathrm{~L}$ soft-agar CD-ST $\left(28{ }^{\circ} \mathrm{C}, 3-4\right.$ days) and extracted overnight with $2 \mathrm{~L}$ acetone. The acetone extracts were concentrated by rotary evaporation, and the residual aqueous layer was extracted with EtOAc $(3 \times 750 \mathrm{~mL})$. The EtOAc layers from all extractions were combined and concentrated by rotary evaporation, re-dissolved in $\mathrm{MeOH}$, and adsorbed onto $5 \mathrm{~g}$ Celite for dry loading for separation on the CombiFlash system. A normal phase EtOAc/hexanes gradient $(25 \%$ EtOAc for $5 \mathrm{~min}$, followed by a linear gradient of 25\%-100\% EtOAc for $15 \mathrm{~min}$, followed by 100\% EtOAc for $5 \mathrm{~min}$ ) was applied for the initial separation of target compounds. Fractions containing the target compounds were identified by LC-MS and combined for further purification by HPLC.

HPLC purification was performed on the Thermo Scientific ${ }^{\mathrm{TM}}$ UltiMate $^{\mathrm{TM}} 3000$ Basic Automated System with a semipreparative reverse-phase $\mathrm{C} 18$ column (Phenomenex Kinetex, $5 \mu \mathrm{m}, 100 \AA$, $10 \times 250 \mathrm{~mm}$ ). A linear gradient of 75-95\% $\mathrm{MeCN} / \mathrm{H}_{2} \mathrm{O}$ in 11.5 minutes, followed by $95 \% \mathrm{MeCN} / \mathrm{H}_{2} \mathrm{O}$ for 10 minutes, followed by $75 \% \mathrm{MeCN} / \mathrm{H}_{2} \mathrm{O}$ for 3.5 minutes with a flow rate of $3 \mathrm{~mL} / \mathrm{min}$. was applied for each sample. HPLC fractions containing pure samples of the desired compounds were identified by LC-MS, combined, and dried under reduced pressure to yield the final compounds. Highresolution mass spectrometry (HRMS) analyses were performed on the Agilent Technologies 6545 Accurate Mass QTOF LC/MS with a reverse-phase column (Agilent InfinityLab Poroshell $120 \mathrm{ECC} 18,2.7 \mu \mathrm{m}, 3.0 \times 50 \mathrm{~mm}$ ) using positive electrospray ionization with $50 \% \mathrm{MeCN} / \mathrm{H}_{2} \mathrm{O}$ for 2 minutes, followed by a linear gradient of $50-95 \% \mathrm{MeCN} / \mathrm{H}_{2} \mathrm{O}$ for 13 minutes, with a flow rate of $0.4 \mathrm{~mL} / \mathrm{min}$. The $\mathrm{MeCN}$ and $\mathrm{H}_{2} \mathrm{O}$ for the HPLC and HRMS were supplemented with $0.1 \% \mathrm{v} / \mathrm{v}$ formic acid.

Compound 6 was isolated as a light orange solid at $2 \mathrm{mg} / \mathrm{L}$ yield $\left(\mathrm{HRMS} m / z\right.$ : $[\mathrm{M}+\mathrm{H}]^{+}$calculated for $\mathrm{C}_{27} \mathrm{H}_{40} \mathrm{NO}_{3}$ 426.2801; found 426.2802). Compound 7 was isolated as a white crystalline solid at $15 \mathrm{mg} / \mathrm{L}$ yield (HRMS $m / z:[\mathrm{M}+\mathrm{H}]^{+}$ 
calculated for $\mathrm{C}_{27} \mathrm{H}_{38} \mathrm{NO}_{3} 424.2852$; found 424.2875). Compound 7' was isolated as a white powder at $<1 \mathrm{mg} / \mathrm{L}$ yield (HRMS m/z: [M+H] ${ }^{+}$calculated for $\mathrm{C}_{27} \mathrm{H}_{38} \mathrm{NO}_{4}$ 440.2801; found 440.2803). Compound 13 was isolated as a light yellow solid at $3.7 \mathrm{mg} / \mathrm{L}$ yield (HRMS m/z: $[\mathrm{M}+\mathrm{H}]^{+}$calculated for $\mathrm{C}_{27} \mathrm{H}_{38} \mathrm{NO}_{3}$ 424.2852; found 424.2852). Compound 2 was isolated as a light yellow solid at $2 \mathrm{mg} / \mathrm{L}$ yield (HRMS $m / z$ : $[\mathrm{M}+\mathrm{H}]^{+}$calculated for $\mathrm{C}_{27} \mathrm{H}_{38} \mathrm{NO}_{4}$ 440.2801; found 440.2801).

\subsection{Purification and biochemical characterization of SmbG}

The intron-free cDNA of SmbG was amplified from the cDNA library of AnEB106 and ligated into PCR-amplified modified pET28a (+) vector (Addgene plasmid \#29656) backbone by HiFi DNA Assembly (NEB). The assembly reaction mixture was transformed into chemically competent $E$. coli DH5 $\alpha$ cells to obtain pEB115.

E. coli BL21 (DE3) cells harboring pEB115 was grown overnight in LB medium ( $5 \mathrm{~mL}$, supplemented with $50 \mu \mathrm{g} / \mathrm{mL}$ kanamycin) and inoculated into larger-scale LB medium ( $1 \mathrm{~L}$, supplemented with $50 \mu \mathrm{g} / \mathrm{mL}$ kanamycin). Once the optical density $\left(\mathrm{OD}_{600}\right)$ of the culture reached 0.6 , it was chilled on ice for $30 \mathrm{~min}$, and protein expression was induced with 0.1 $\mathrm{mM}$ IPTG $\left(250 \mathrm{rpm}, 16^{\circ} \mathrm{C}, 16 \mathrm{~h}\right)$.

Cells were harvested by centrifugation (4300 rpm, $15 \mathrm{~min}$ ), re-suspended in $30 \mathrm{~mL}$ A10 buffer (10 mM imidazole, $50 \mathrm{mM}$ Tris- $\mathrm{HCl}, 100 \mathrm{mM} \mathrm{NaCl} ; \mathrm{pH} \mathrm{8.0)}$ and lysed by sonication on ice. The insoluble debris was removed from the lysate by centrifugation $\left(17,000 \mathrm{~g}, 15 \mathrm{~min}, 4^{\circ} \mathrm{C}\right)$, and the soluble fractions were incubated with the Ni-NTA resin (Qiagen) $\left(4^{\circ} \mathrm{C}, 12\right.$ h) for protein loading. The protein was eluted by sequentially washing the resin with buffers containing increasing concentrations of imidazole $(50 \mathrm{mM}, 100 \mathrm{mM}, 200 \mathrm{mM} ; 50 \mathrm{~mL}$ per wash). The purified proteins were concentrated and exchanged into storage buffer (50 mM phosphate buffer, $100 \mathrm{mM} \mathrm{NaCl}, 10 \%$ glycerol, $\mathrm{pH} 8.0$ ) with Centriprep filters (Amicon) and flash-frozen in liquid $\mathrm{N}_{2}$ as $10-\mu \mathrm{L}$ aliquots for storage at $-80{ }^{\circ} \mathrm{C}$ until use.

To verify the proposed $N$-methyltransferase activity of SmbG, conversion of $N$-demethylsambutoxin (2) to sambutoxin (1) in the presence of SmbG and $S$-adenosylmethionine (SAM) was monitored by LC-MS. $10 \mu \mathrm{L}$ reaction mixtures with $1 \mathrm{mM}$ SAM and varying concentrations of $\mathbf{3}$ were prepared, and $\mathrm{SmbG}$ was added at a final concentration of $1 \mu \mathrm{M}$ to initiate the reactions. The reactions were also run with varying concentrations of $\mathbf{1 3}$ to explore the substrate specificity of SmbG (Figure S5).

\subsection{Spectrometric analysis}

NMR spectra were obtained on the Bruker AV500 spectrometer with $5 \mathrm{~mm}$ dual cryoprobe at the UCLA Molecular Instrumentation Center $\left({ }^{1} \mathrm{H} 500 \mathrm{MHz},{ }^{13} \mathrm{C} 125 \mathrm{MHz}\right)$. Chemical shifts are reported in parts per million (ppm) using the resonance of deuterated solvent as reference $\left(\mathrm{CDCl}_{3}: \delta_{\mathrm{H}}=7.26, \delta_{\mathrm{C}}=77.16\right.$; DMSO- $\left.d_{6}: \delta_{\mathrm{H}}=2.50, \delta_{\mathrm{C}}=39.52\right)$. Optical rotation was measured on the Rudolph Research Autopol III automatic polarimeter.

\subsection{Electron diffraction data collection, refinement and statistics for compound 13}

Compound 9 was recrystallized by slow evaporation of the HPLC fraction in MeCN/ $\mathrm{H}_{2} \mathrm{O}$. Microcrystals were deposited onto a pure carbon EM grid and transferred to the FEI Tecnai F200C transmission electron microscope (operating voltage of $200 \mathrm{keV}$, wavelength of $0.025 \AA$ ) on a Gatan 626 cryo-holder at ambient temperature $(273 \mathrm{~K})$. The sample was cooled to cryogenic temperature $(100 \mathrm{~K})$ after insertion. Diffraction data acquisition, conversion and reduction were performed as described previously. ${ }^{2}$ Data from two crystals were scaled and merged together to produce the final data set for 2 , before converting the intensities to SHELX format. Structure of $\mathbf{2}$ was solved $a b$ initio using direct methods in SHELXD Shd $^{3}$ refined with SHELXL ${ }^{4}$ in ShelXle ${ }^{5}$, refining all non-hydrogen atoms anisotropically and placing hydrogen atoms using the riding model. Residual density belonging to solvent molecules was observed, but solvent molecules could not be placed due to disorder. 
Table S1. Deduced functions of open reading frames in the smb cluster from $F$. commune.

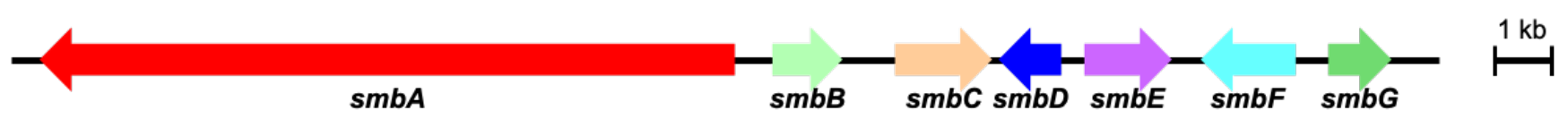

\begin{tabular}{c|c|c|c} 
Gene & Size (aa) & Proposed function & \% Identity with lep homolog \\
\hline$s m b A$ & 3932 & PKS-NRPS & $44 \%$ \\
$s m b B$ & 365 & trans-enoyl reductase & $49 \%$ \\
$s m b C$ & 507 & ring-expansion P450 & $60 \%$ \\
$s m b D$ & 327 & short-chain dehydrogenase/reductase & $32 \%$ \\
$s m b E$ & 527 & P450 & -- \\
$s m b F$ & 503 & P450 & -- \\
$s m b G$ & 310 & $N$-methyltransferase & --
\end{tabular}


Table S2. Primers used in this study.

\begin{tabular}{|c|c|}
\hline Primer & Sequence $5^{\prime} \rightarrow 3^{\prime}$ \\
\hline pYTU_SmbA_F1 & CTTCATCCCCAGCATCATTACACCTCAGCAATGCCATCCCCAGGCGAG \\
\hline pYTU_SmbA_R1 & TTGAGATCAGCTTGCTCAGG \\
\hline pYTU_SmbA_F2 & ATGGCTATGGCTATCCAAGC \\
\hline pYTU_SmbA_R2 & AAAAGCGAGGGTTGTTGACC \\
\hline pYTU_SmbA_F3 & ACTTGTATGAGGGCATCAGC \\
\hline pYTU_SmbA_R3 & ACTGTCGTCTCCATCATCGT \\
\hline pYTU_SmbA_F4 & TTACGCCGAACAATGACACG \\
\hline pYTU_SmbA_R4 & GAGGACATACCCGTAATTTTCTGGCGGCCGCCTACGTGTTAATTAACACATTCCAGTCTG \\
\hline pYTR_SmbB_F & ATTACCCCGCCACATAGACACATCTAAACAATGGCAGTCCAATCAATCATC \\
\hline pYTR_SmbB_R & TGCTAAAGGGTATCATCGAAAGGGAGTCATCCAGGATCCCAAAAGCAAGGTTTGAAGTGC \\
\hline pYTR_SmbC_F & GCATACAGAACACTTCAAACAATCGCAAAAATGTCATCTCGTCTCTCCG \\
\hline pYTR_SmbC_R & AGACCCAACAACCATGATACCAGGGGGCTAGCTTAATTAAAGCCATTGATGGTGCTTGTG \\
\hline pYTP_SmbD_F & GGGGTGTGATGACGACATTGTTTAGATGTGTCTATGTGGC \\
\hline pYTP_SmbD_R & AACAACCATGATACCAGGGGGCTAGCCGATACTTAATTAACTGTAACCGCTATCTGATGC \\
\hline pYTP_SmbE_F & CTTATACATGATCTAACAATTCTAGTAAACCGCAATCATGACAAACCCCACAAACATTAC \\
\hline pYTP_SmbE_R & AACAACCATGATACCAGGGGGGATCCTAGTCCTTAATTAAAAGGTTCCGTAAGCTTGACG \\
\hline pYTP_SmbF_F & ACAGAACACTTCAAACAATCGCAAAAATGGAAAATTTGCAATTGAACG \\
\hline pYTP_SmbF_R & AACAACCATGATACCAGGGGCTAGCGGTACCTTAATTAATTGATATTGCGCTTACGTCTG \\
\hline pYTR_SmbG_F1 & ACTCCGGTGAATTGATTTGGG \\
\hline pYTR_SmbG_R1 & GGGAGATTGGTTCACTGCTTCAGTAGCCATTGTTTAGATGTGTCTATGTGGC \\
\hline pYTR_SmbG_F2 & ATGGCTACTGAAGCAGTG \\
\hline pYTR_SmbG_R2 & AGACCCAACAACCATGATACCAGGGGGGATCCTTAATTAAAATCCTACCAATATTAGCGTTGC \\
\hline pYTR_SmbBC__F & CCAACTTTAATACGCAATAAGACACCATAGTTTGCTCCAGGAATACATGTG \\
\hline pYTR_SmbBC_R & TCATCGAAAGGGAGTCATCCAGGATCCAGCGCTTAATTAATGTACTAGCTGGGAAGATCG \\
\hline pYTU_SmbABC_F1 & ATTCAGAGAAGGTACTAAGGATGTCGATGGACTCCGGTGAATTGATTTGGG \\
\hline pYTU_SmbABC_R1 & TCGAGCTGCATTCATAGTCC \\
\hline pYTU_SmbABC_F2 & ACACTTCAGGGTTGTGGAAAATATCAGGCTTTTGCTCCAGGAATACATGTG \\
\hline pYTU_SmbABC_R2 & GGACATACCCGTAATTTTCTGGCGGCCGCTACTTAATTAAACCTCTGCACCAGTTTATCC \\
\hline pYTP_SmbDE_F & CAGGGTCGCGATGCATCAGATAGCGGTTACAGGATTCGTCCAGGGCTTCC \\
\hline pYTP_SmbDE_R & AACAACCATGATACCAGGGGGGATCCTAGTCCTTAATTAAAAGGTTCCGTAAGCTTGACG \\
\hline pYTP_SmbDEF_F & GGACTGATTCGTCAAGCTTACGGAACCTTTTTGCTCCAGGAATACATGTG \\
\hline pYTP_SmbDEF_R & ACAACCATGATACCAGGGGGGATCCTAGTCCTTAATTAATTGATATTGCGCTTACGTCTG \\
\hline pET28a_SmbG_F & TAGAAATAATTTTGTTTAACTTTAAGAAGGAGATATACCATGGCTACTGAAGCAGTGAAC \\
\hline pET28a_SmbG_R & GCCGGATCTCAGTGGTGGTGGTGGTGGTGCTCCTTCTTAGGCTTCAATCCTC \\
\hline
\end{tabular}


Table S3. Plasmids used in this study.

\begin{tabular}{l|l|l} 
Plasmid & Vector & Description (promoter-gene) \\
\hline pEB101 & pYTP & Vector only \\
pEB102 & pYTR & Vector only \\
pEB103 & pYTU & Vector only \\
pEB104 & pYTU & glaA-SmbA \\
pEB105 & pYTR & ANgpdA-SmbB \\
pEB106 & pYTP & POgpdA-SmbC \\
pEB107 & pYTP & ANgpdA-SmbD \\
pEB108 & pYTP & PEgpdA-SmbE \\
pEB109 & pYTP & POgpdA-SmbF \\
pEB110 & pYTR & ANgpdA-SmbG \\
pEB111 & pYTR & ANgpdA-SmbB; POgpdA-SmbC \\
pEB112 & pYTU & glaA-SmbA; ANgpdA-SmbB; POgpdA-SmbC \\
pEB113 & pYTP & ANgpdA-SmbD; PEgpdA-SmbE \\
pEB114 & pYTP & ANgpdA-SmbD; PEgpdA-SmbE; POgpdA-SmbF \\
pEB115 & pET28a & T7-SmbG- $N-H i s$
\end{tabular}

Table S4. A. nidulans transformants prepared in this study.

\begin{tabular}{c|c|c} 
Transformant & Description (plasmids) & Major compound produced \\
\hline AnEB101 & $\mathrm{p} E B 101, \mathrm{pEB} 104, \mathrm{pEB} 105$ & $\mathbf{6}$ \\
AnEB102 & $\mathrm{pEB} 104, \mathrm{pEB} 105, \mathrm{pEB} 106$ & $\mathbf{7}$ \\
AnEB103 & $\mathrm{pEB} 104, \mathrm{pEB} 111, \mathrm{pEB} 107$ & \\
AnEB104 & $\mathrm{pEB} 104, \mathrm{pEB} 111, \mathrm{pEB} 113$ & $\mathbf{1 3}$ \\
AnEB105 & $\mathrm{pEB} 104, \mathrm{pEB} 111, \mathrm{pEB} 114$ & $\mathbf{2}$ \\
AnEB106 & $\mathrm{pEB} 112, \mathrm{pEB} 110, \mathrm{pEB} 114$ & $\mathbf{1}$ (detected)
\end{tabular}


Table S5. Structural characterization of 6.
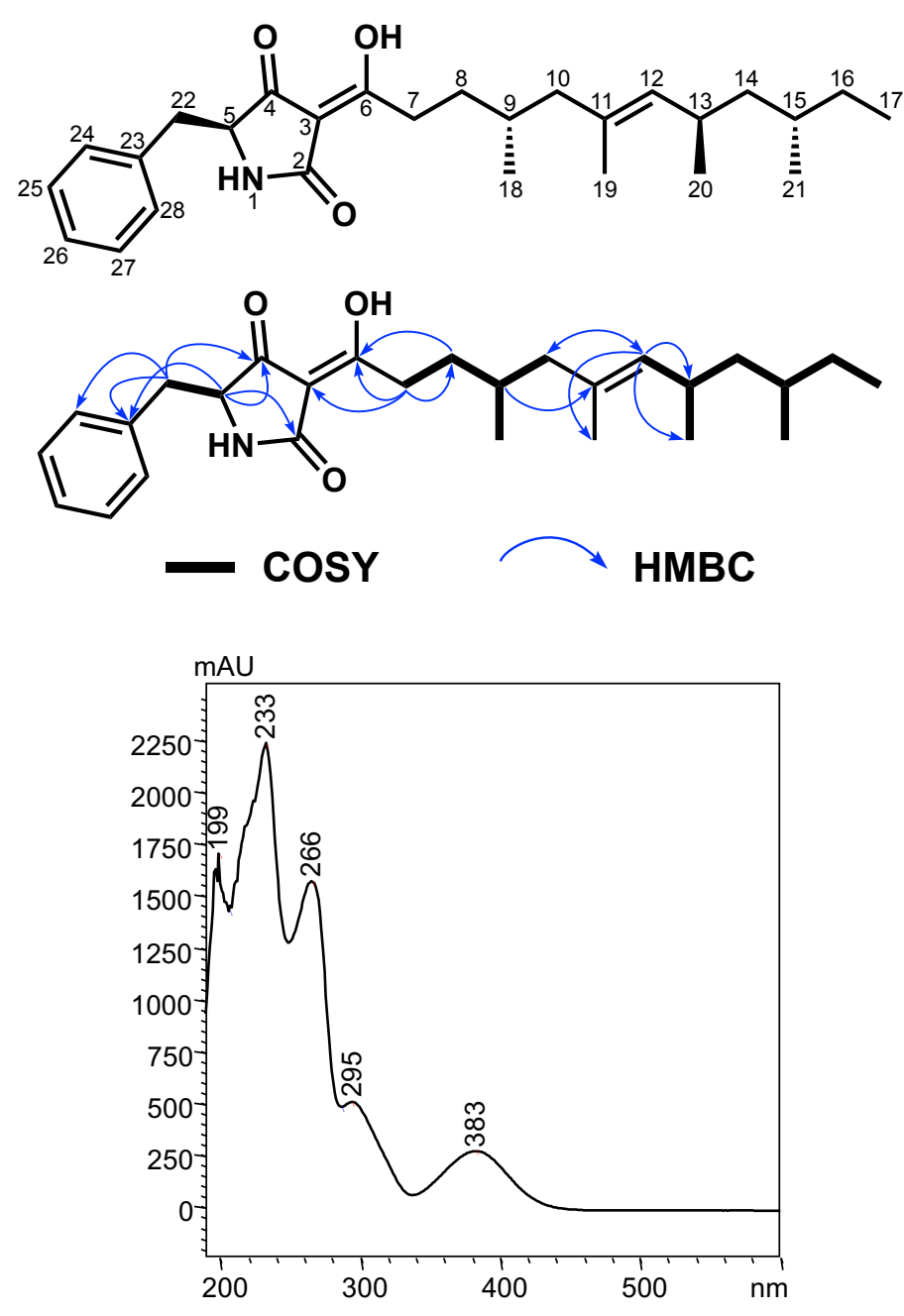

${ }^{1} \mathrm{H}-\mathrm{NMR}(500 \mathrm{MHz}),{ }^{13} \mathrm{C}-\mathrm{NMR}$ (125 MHz), DMSO- $d_{6}$

\begin{tabular}{|c|c|c|}
\hline Position & $\delta_{H}$ & $\delta c$ \\
\hline $1-\mathrm{NH}$ & -- & -- \\
\hline 2 & -- & 174.6 \\
\hline 3 & -- & 101.1 \\
\hline 4 & -- & 194.6 \\
\hline 5 & $4.16(\mathrm{t}, J=5.0 \mathrm{~Hz})$ & 61.9 \\
\hline 6 & -- & 188.7 \\
\hline 7 & $2.73(\mathrm{~m}), 2.65(\mathrm{~m})$ & 29.9 \\
\hline 8 & $1.47(\mathrm{~m}), 1.24(\mathrm{~m})$ & 32.2 \\
\hline 9 & 1.55 & 29.4 \\
\hline 10 & $1.94(\mathrm{~m}), 1.68(\mathrm{~m})$ & 46.9 \\
\hline 11 & -- & 131.0 \\
\hline 12 & $4.85(\mathrm{~d}, J=9.5 \mathrm{~Hz})$ & 133.2 \\
\hline 13 & $2.41(\mathrm{~m})$ & 29.4 \\
\hline 14 & $1.17(\mathrm{~m}), 1.02(\mathrm{~m})$ & 44.6 \\
\hline 15 & $1.32(\mathrm{~m})$ & 31.5 \\
\hline 16 & $1.32(\mathrm{~m}), 1.02(\mathrm{~m})$ & 28.4 \\
\hline 17 & $0.81(\mathrm{t}, J=6.0 \mathrm{~Hz})$ & 11.1 \\
\hline 18 & $0.77(\mathrm{~d}, J=6.5 \mathrm{~Hz}))$ & 18.8 \\
\hline 19 & $1.51(\mathrm{~d}, J=1.0 \mathrm{~Hz})$ & 15.7 \\
\hline 20 & $0.85(\mathrm{~d}, J=7.0 \mathrm{~Hz}))$ & 21.2 \\
\hline 21 & $0.81(\mathrm{~d}, J=7.0 \mathrm{~Hz})$ & 19.6 \\
\hline 22 & $2.96(\mathrm{~m}), 2.90(\mathrm{~m})$ & 36.6 \\
\hline 23 & -- & 135.8 \\
\hline $24 / 28$ & $7.14-7.25(\mathrm{~m})$ & 129.7 \\
\hline $25 / 27$ & 7.14-7.25 (m) & 128.0 \\
\hline 26 & $7.14-7.25(\mathrm{~m})$ & 126.5 \\
\hline
\end{tabular}


Table S6 Structural characterization of 7.
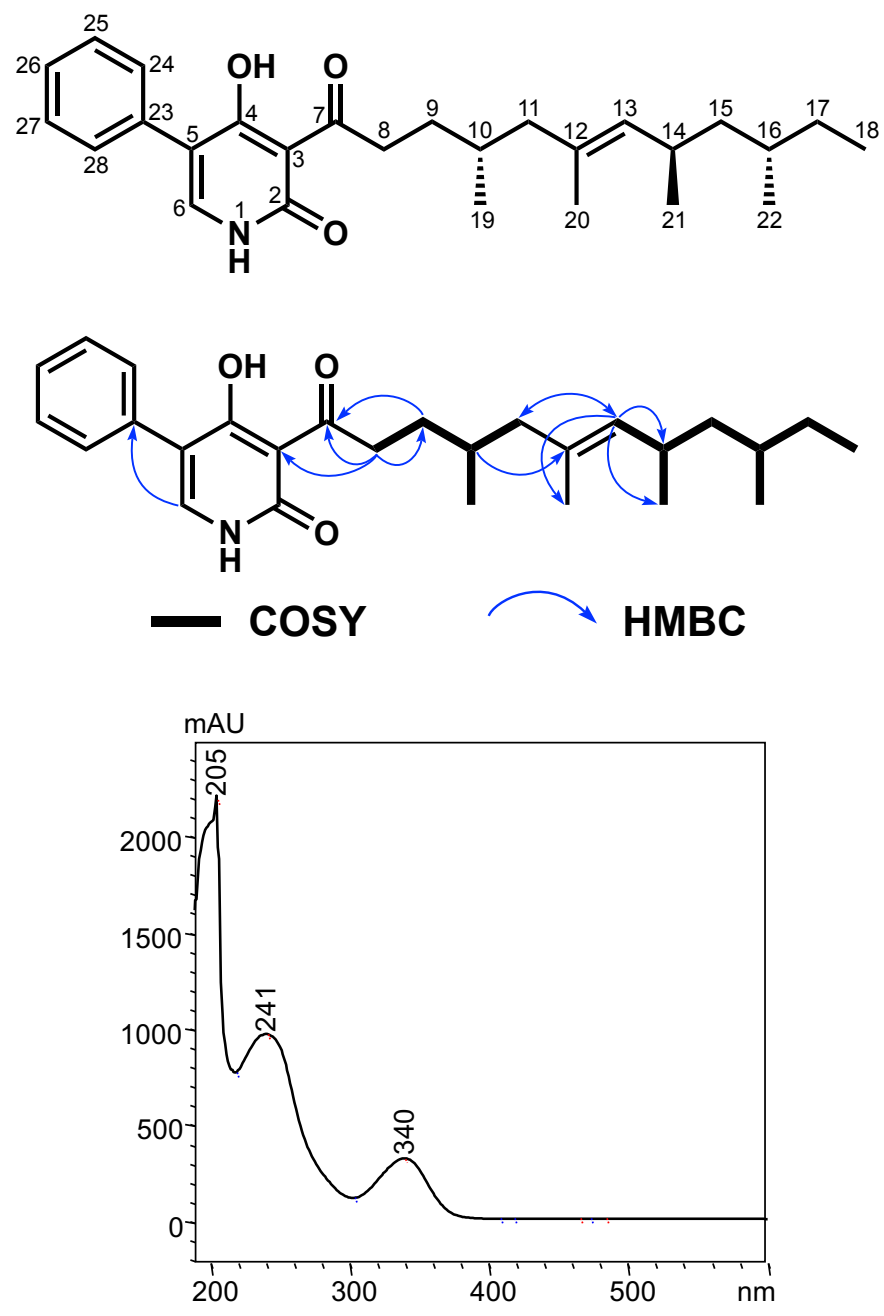

${ }^{1} \mathrm{H}-\mathrm{NMR}(500 \mathrm{MHz}),{ }^{13} \mathrm{C}-\mathrm{NMR}(125 \mathrm{MHz}), \mathrm{CDCl}_{3}$

\begin{tabular}{c|c|c} 
Position & $\delta_{\mathrm{H}}$ & $\boldsymbol{\delta}_{\mathrm{c}}$ \\
\hline 1 & -- & -- \\
2 & -- & 163.1 \\
3 & -- & 106.2 \\
4 & -- & 176.3 \\
5 & -- & 115.3 \\
6 & $7.42(\mathrm{~s})$ & 138.5 \\
7 & -- & 209.2 \\
8 & $3.25(\mathrm{~m})$ & 40.7 \\
9 & $1.49(\mathrm{~m}), 1.72(\mathrm{~m})$ & 31.3 \\
10 & $1.71(\mathrm{~m})$ & 30.5 \\
11 & $1.07(\mathrm{~m}), 1.77(\mathrm{~m})$ & 47.8 \\
12 & -- & 131.4 \\
13 & $4.89(\mathrm{~d}, J=9.8 \mathrm{~Hz})$ & 133.8 \\
14 & $2.45(\mathrm{~m})$ & 29.8 \\
15 & $1.02,1.18$ & 45.1 \\
16 & $1.29(\mathrm{~m})$ & 32.0 \\
17 & $1.03(\mathrm{~m}), 1.33(\mathrm{~m})$ & 29.1 \\
18 & $0.84(\mathrm{~m})$ & 11.3 \\
19 & $0.74(\mathrm{~d}, J=6.6 \mathrm{~Hz})$ & 19.6 \\
20 & $1.56(\mathrm{~s})$ & 15.9 \\
21 & $0.90(\mathrm{~d}, J=6.6 \mathrm{~Hz})$ & 21.1 \\
22 & $0.87(\mathrm{~m})$ & 19.2 \\
23 & -- & 132.8 \\
$24 / 28$ & $7.35-7.46(\mathrm{~m})$ & 129.0 \\
$25 / 27$ & $7.35-7.46(\mathrm{~m})$ & 128.5 \\
26 & $7.35-7.46(\mathrm{~m})$ & 128.0
\end{tabular}


Table S7. Structural characterization of 7'.
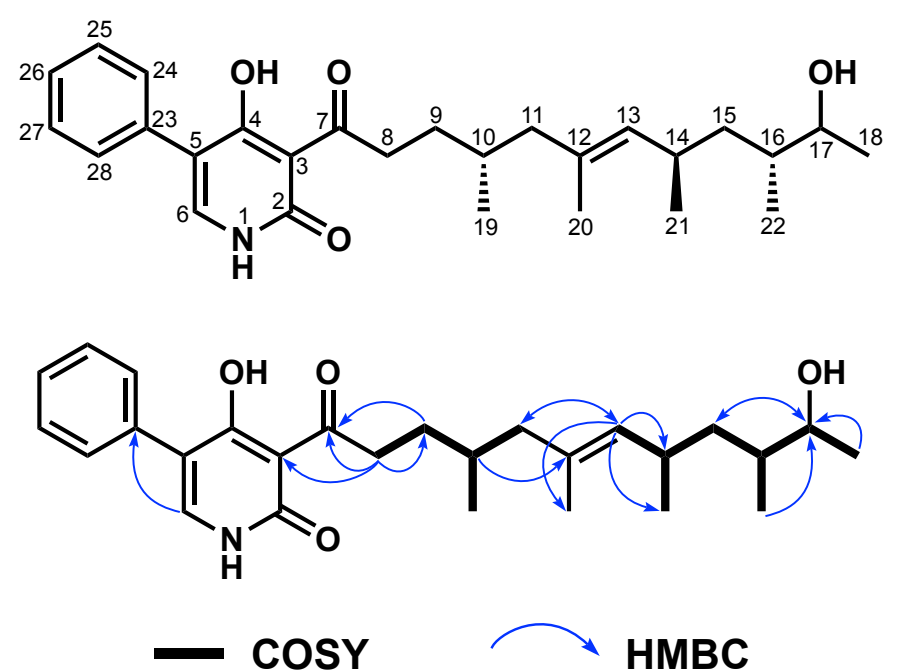

HMBC

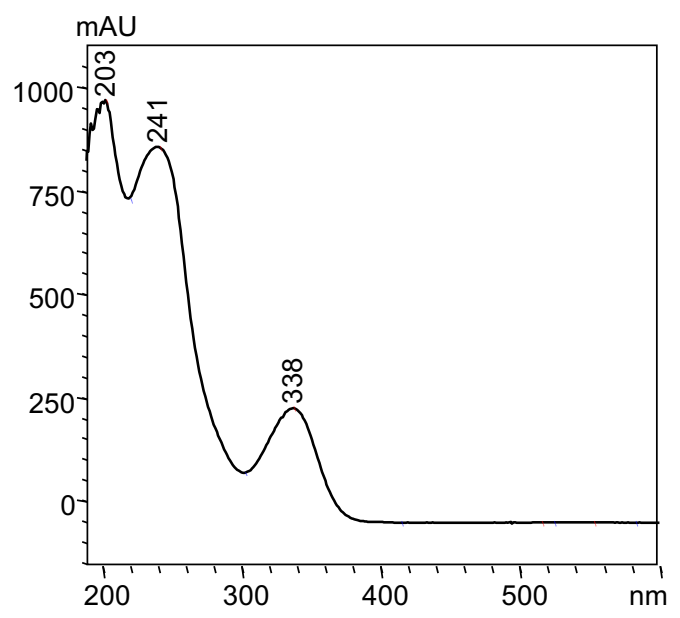

${ }^{1} \mathrm{H}-\mathrm{NMR}$ (500 MHz), ${ }^{13} \mathrm{C}-\mathrm{NMR}$ (125 MHz), $\mathrm{CDCl}_{3}$

\begin{tabular}{c|c|c} 
Position & $\delta_{H}$ & $\delta_{\mathrm{c}}$ \\
\hline 1 & -- & -- \\
2 & -- & 163.7 \\
3 & -- & 106.7 \\
4 & -- & 176.2 \\
5 & -- & 115.4 \\
6 & $7.43(\mathrm{~s})$ & 138.8 \\
7 & -- & 209.2 \\
8 & $3.25(\mathrm{~m})$ & 40.8 \\
9 & $1.47(\mathrm{~m}), 1.75(\mathrm{~m})$ & 31.3 \\
10 & $1.73(\mathrm{~m})$ & 30.6 \\
11 & $1.80(\mathrm{~m}), 2.04(\mathrm{~m})$ & 47.7 \\
12 & -- & 131.8 \\
13 & $4.93(\mathrm{~d}, \mathrm{~J}=9.4 \mathrm{~Hz})$ & 138.8 \\
14 & $2.45(\mathrm{~m})$ & 29.8 \\
15 & $1.07(\mathrm{~m}), 1.36(\mathrm{~m})$ & 40.8 \\
16 & $1.48(\mathrm{~m})$ & 37.1 \\
17 & $3.72(\mathrm{~m})$ & 70.7 \\
18 & $1.13(\mathrm{~m})$ & 20.8 \\
19 & $0.87(\mathrm{~m})$ & 19.4 \\
20 & $1.57(\mathrm{~s})$ & 16.1 \\
21 & $0.90(\mathrm{~d}, \mathrm{~J}=6.6 \mathrm{~Hz})$ & 20.5 \\
22 & $0.87(\mathrm{~m})$ & 14.1 \\
23 & -- & 132.6 \\
$24 / 28$ & $7.35-7.46(\mathrm{~m})$ & 129.0 \\
$25 / 27$ & $7.35-7.46(\mathrm{~m})$ & 128.5 \\
26 & $7.35-7.46(\mathrm{~m})$ & 128.0 \\
& &
\end{tabular}


Table S8. Structural characterization of $\mathbf{1 3 .}$
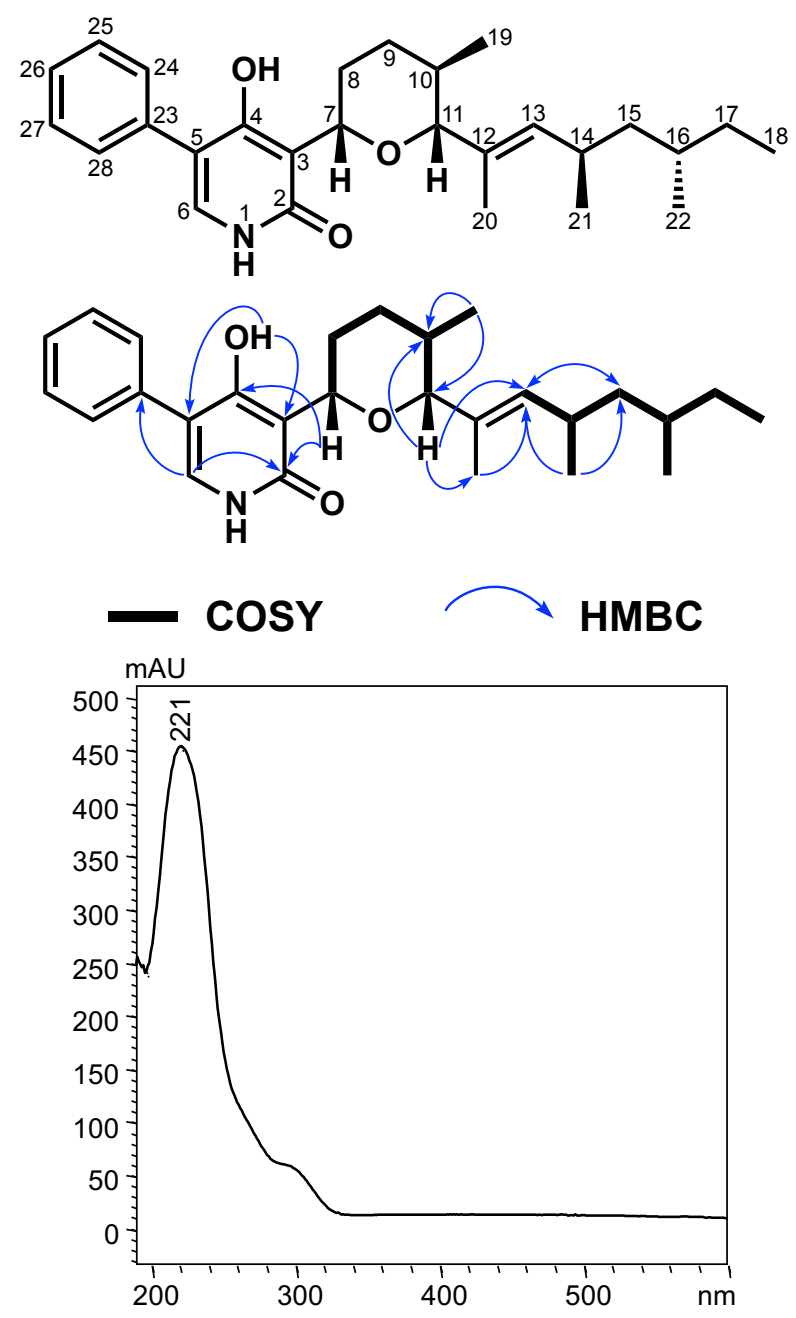

$[\alpha]_{D}^{25}-116^{\circ}(c=0.25, \mathrm{MeOH})$
${ }^{1} \mathrm{H}-\mathrm{NMR}(500 \mathrm{MHz}),{ }^{13} \mathrm{C}-\mathrm{NMR}(125 \mathrm{MHz}), \mathrm{CDCl}_{3}$

\begin{tabular}{c|c|c} 
Position & $\boldsymbol{\delta}_{\mathbf{H}}$ & $\boldsymbol{\delta} \mathrm{c}$ \\
\hline 1 & -- & -- \\
2 & -- & 163.7 \\
3 & -- & 110.4 \\
4 & -- & 163.8 \\
5 & -- & 116.0 \\
6 & $7.28(\mathrm{~s})$ & 134.1 \\
7 & $5.03(\mathrm{~d}, J=11.5 \mathrm{~Hz})$ & 76.9 \\
8 & $1.69(\mathrm{~m}), 2.09(\mathrm{~m})$ & 30.9 \\
9 & $1.46(\mathrm{~m}), 1.93(\mathrm{~m})$ & 32.1 \\
10 & $1.70(\mathrm{~m})$ & 32.4 \\
11 & $3.54(\mathrm{~d}, J=10.0 \mathrm{~Hz})$ & 92.8 \\
12 & -- & 130.3 \\
13 & $5.20(\mathrm{~d}, J=9.5 \mathrm{~Hz})$ & 138.2 \\
14 & $2.48(\mathrm{~m})$ & 29.7 \\
15 & $1.05(\mathrm{~m}), 1.21(\mathrm{~m})$ & 44.8 \\
16 & $1.33(\mathrm{~m})$ & 32.3 \\
17 & $1.05,1.33(\mathrm{~m})$ & 29.0 \\
18 & $0.84(\mathrm{~m})$ & 11.7 \\
19 & $0.76(\mathrm{~d}, J=6.6 \mathrm{~Hz})$ & 17.8 \\
20 & $1.63(\mathrm{~s})$ & 11.3 \\
21 & $0.91(\mathrm{~d}, J=6.6 \mathrm{~Hz})$ & 20.8 \\
22 & $0.84(\mathrm{~m})$ & 19.7 \\
23 & -- & 133.1 \\
$24 / 28$ & $7.39(\mathrm{~d}, J=7.8 \mathrm{~Hz})$ & 129.3 \\
$25 / 27$ & $7.45(\mathrm{~m})$ & 128.4 \\
26 & $7.32(\mathrm{~m})$ & 127.5 \\
& &
\end{tabular}


Table S9. Structural characterization of 2.

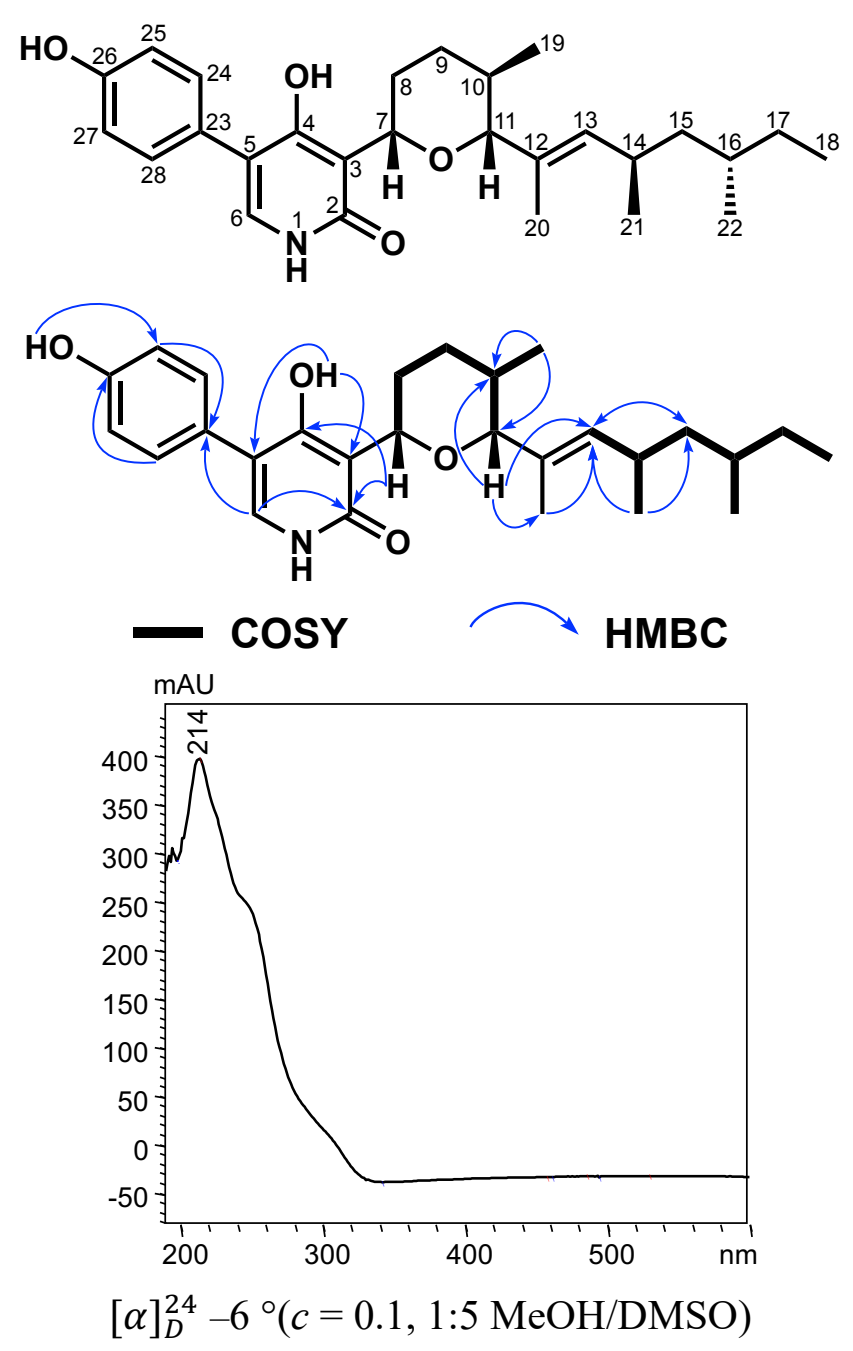

${ }^{1} \mathrm{H}-\mathrm{NMR}(500 \mathrm{MHz}),{ }^{13} \mathrm{C}-\mathrm{NMR}(125 \mathrm{MHz}), \mathrm{CDCl}_{3}$

\begin{tabular}{|c|c|c|}
\hline Position & $\delta_{H}$ & $\delta c$ \\
\hline 1 & -- & -- \\
\hline 2 & -- & 163.5 \\
\hline 3 & -- & 110.4 \\
\hline 4 & -- & 164.4 \\
\hline $4-\mathrm{OH}$ & $10.21(\mathrm{~s})$ & -- \\
\hline 5 & -- & 116.4 \\
\hline 6 & $6.74(\mathrm{~s})$ & 132.8 \\
\hline 7 & $5.03(\mathrm{~d}, J=11.5 \mathrm{~Hz})$ & 77.0 \\
\hline 8 & $1.66(\mathrm{~m}), 2.10(\mathrm{~m})$ & 31.1 \\
\hline 9 & $1.44(\mathrm{~m}), 1.91(\mathrm{~m})$ & 32.1 \\
\hline 10 & $1.68(\mathrm{~m})$ & 32.7 \\
\hline 11 & $3.54(\mathrm{~d}, J=10.0 \mathrm{~Hz})$ & 92.9 \\
\hline 12 & -- & 130.2 \\
\hline 13 & $5.21(\mathrm{~d}, J=9.5 \mathrm{~Hz})$ & 138.4 \\
\hline 14 & $2.45(\mathrm{~m})$ & 29.8 \\
\hline 15 & $1.02(\mathrm{~m}), 1.18(\mathrm{~m})$ & 44.9 \\
\hline 16 & $1.29(\mathrm{~m})$ & 32.1 \\
\hline 17 & $1.03,1.33(\mathrm{~m})$ & 29.0 \\
\hline 18 & $0.83(\mathrm{~m})$ & 11.8 \\
\hline 19 & $0.74(\mathrm{~d}, J=6.6 \mathrm{~Hz})$ & 17.8 \\
\hline 20 & 1.62 (s) & 11.4 \\
\hline 21 & $0.90(\mathrm{~d}, J=6.6 \mathrm{~Hz})$ & 20.9 \\
\hline 22 & $0.84(\mathrm{~m})$ & 19.8 \\
\hline 23 & -- & 125.8 \\
\hline $24 / 28$ & $7.20(\mathrm{~d}, J=8.2 \mathrm{~Hz})$ & 130.7 \\
\hline $25 / 27$ & $6.93(\mathrm{~d}, J=8.4 \mathrm{~Hz})$ & 115.7 \\
\hline 26 & -- & 156.3 \\
\hline
\end{tabular}


A

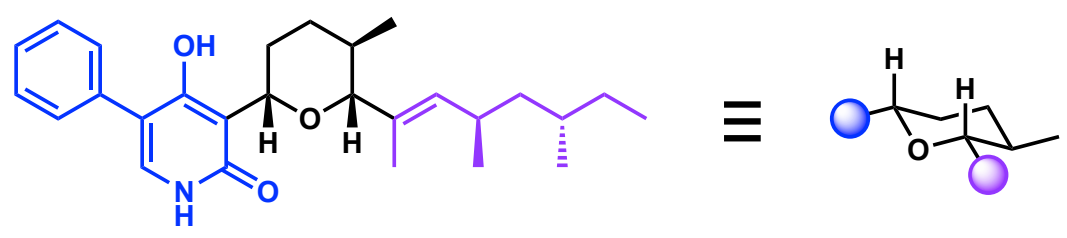

B

MOMO<smiles>c1ccccc1</smiles><smiles>CCC=C1C(=O)C(C)=CN(C)C1=O</smiles><smiles>CCC[C@H](C)[C@@H](O)/C(C)=C/[C@H](C)C[C@@H](C)CC</smiles>

Mомо<smiles>CC[C@H](C)C[C@@H](C)/C=C(\C)[C@H]1O[C@@H](c2c(O)c(-c3ccc([O-])cc3)cn(C)c2=O)CC[C@@H]1C</smiles><smiles>CC[C@H](C)[C@@H](O)[C@@H](C)C[C@H](C)/C=C1/C(=O)C(c2ccccc2)=CN(O)C1=O</smiles><smiles>CC[C@H](C)[C@H]1O[C@](C)(c2c(O)c(-c3ccccc3)cn(O)c2=O)[C@@H](C)C[C@@H]1C</smiles>

septoriamycin $(d r=8: 1)$

Figure S1. Diaxial arrangement of methine hydrogens on the tetrahydropyran. (A) Graphical representation of the bulky substituent groups on $\mathbf{1 3}$ that leads to the preferred diaxial arrangement for the methine hydrogens. (B) Preparation of the tetrahydropyran motif in the total synthesis of (+)-sambutoxin relies on an intramolecular oxaMichael addition. The homologous step in the total synthesis of septoriamycin A favors the diastereomer with diaxial methine hydrogens. ${ }^{6,7}$ 


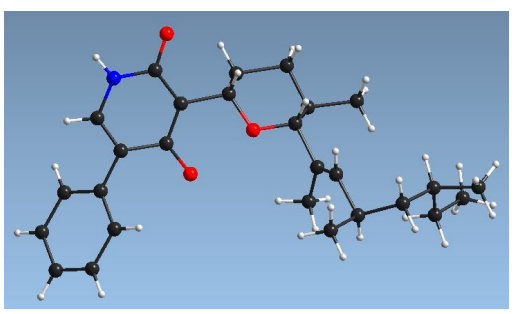

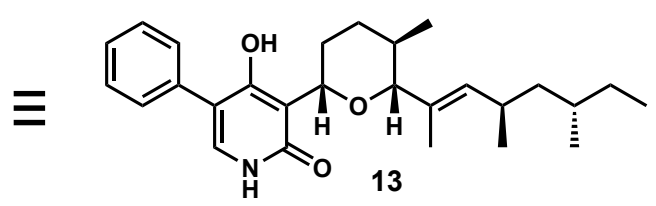

Figure S2. MicroED structure of 13. The relative stereochemistry of compound $\mathbf{1 3}$ is confirmed by MicroED. 


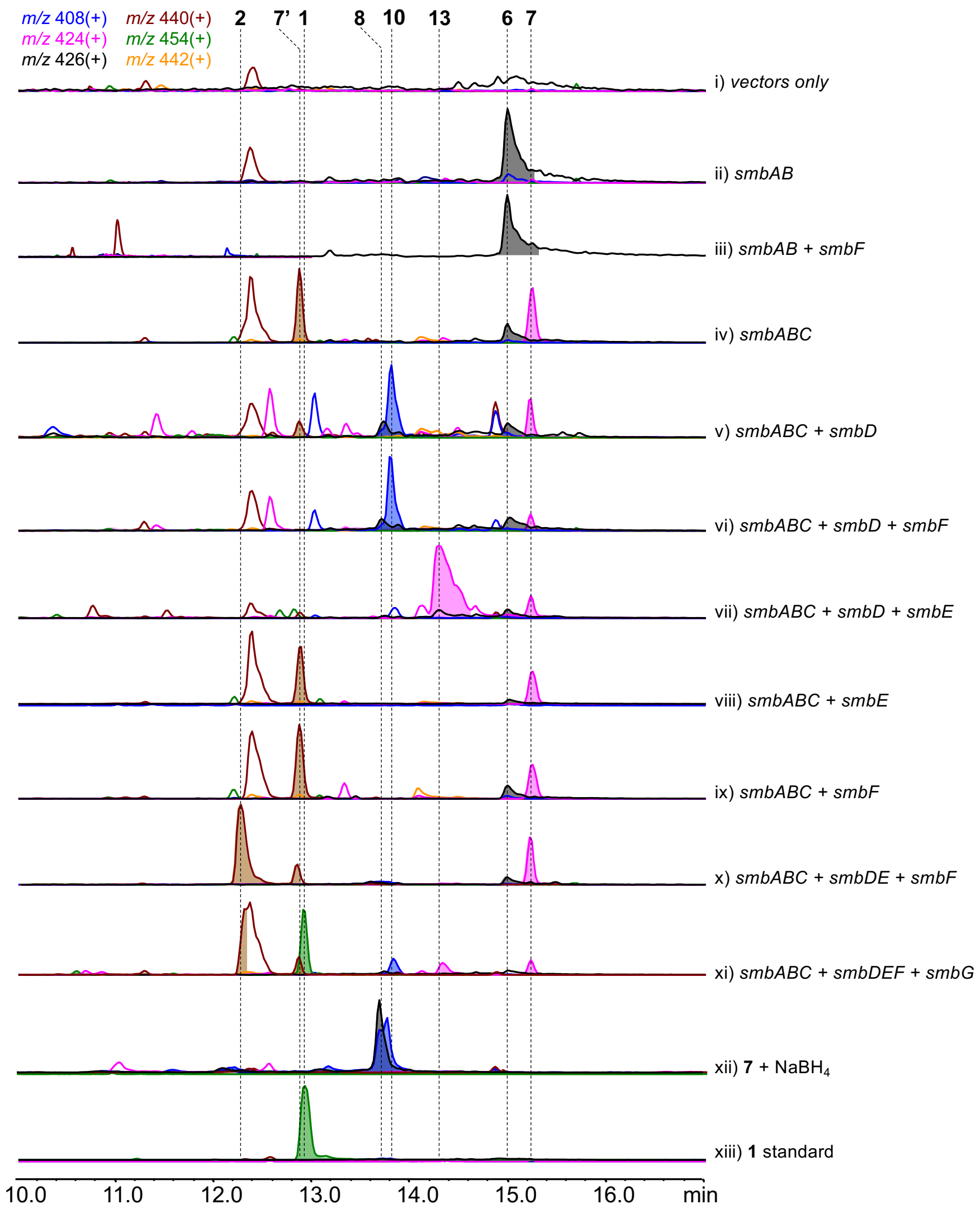

Figure S3. LC-MS analysis of metabolic extracts of A. nidulans expressing $s m b A-G$. The structures of all compounds with the exception of $\mathbf{8}$ and $\mathbf{1 0}$ have been characterized. All traces are shown to scale. 

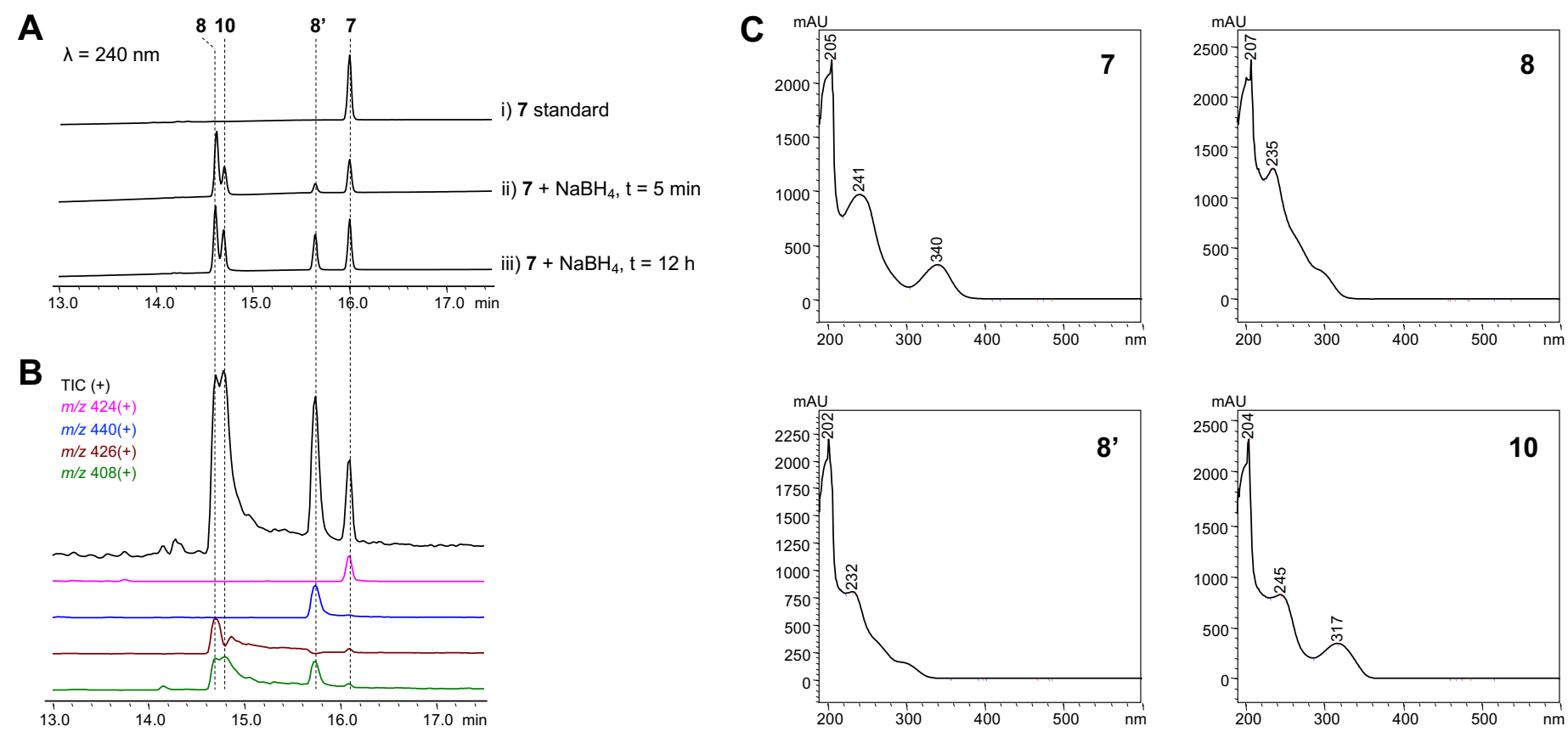

D
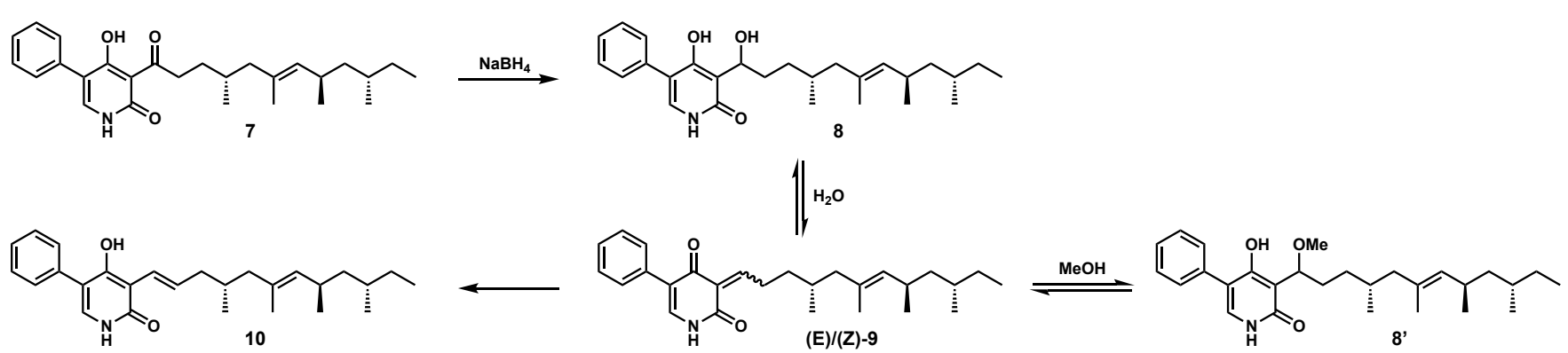

Figure S4. Chemical reduction of 7 with $\mathrm{NaBH}_{4}$. (A) Reaction of $10 \mathrm{mg} 7$ (1 eq.) with $0.8 \mathrm{mg} \mathrm{NaBH} 4$ (0.9 eq.) in $\mathrm{MeOH}(1 \mathrm{~mL})$ resulted in the formation of 3 new products $\left(\mathbf{8}, \mathbf{8}^{\prime}\right.$, and $\left.\mathbf{1 0}\right)$ with conversion of $\mathbf{8}$ to $\mathbf{8}^{\prime}$ and $\mathbf{1 0}$ over time. (B) Extracted ion chromatograms corresponding to $\mathbf{7}$ and products of its $\mathrm{NaBH}_{4}$ reduction. (C) The

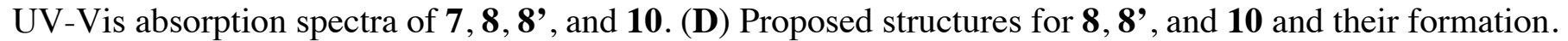




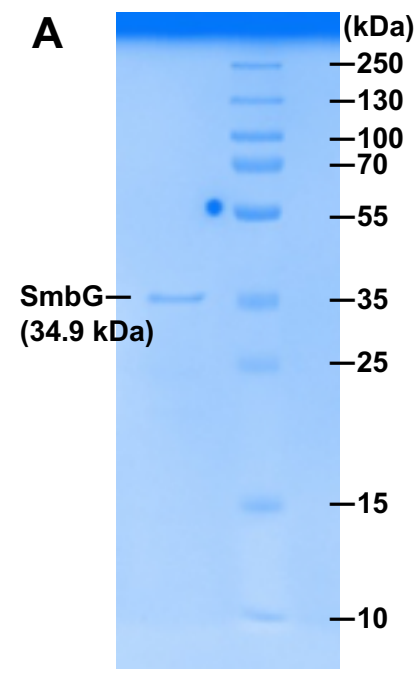

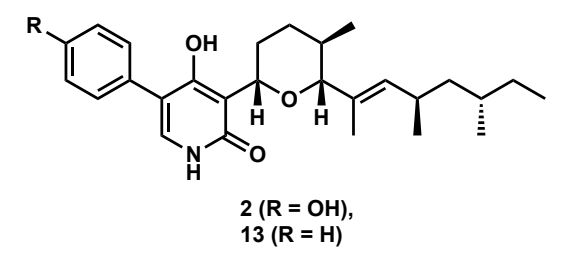

B

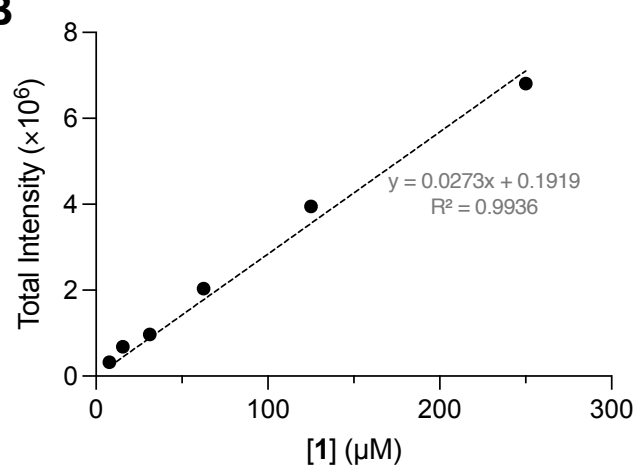

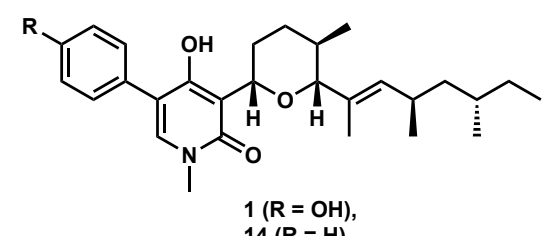

C

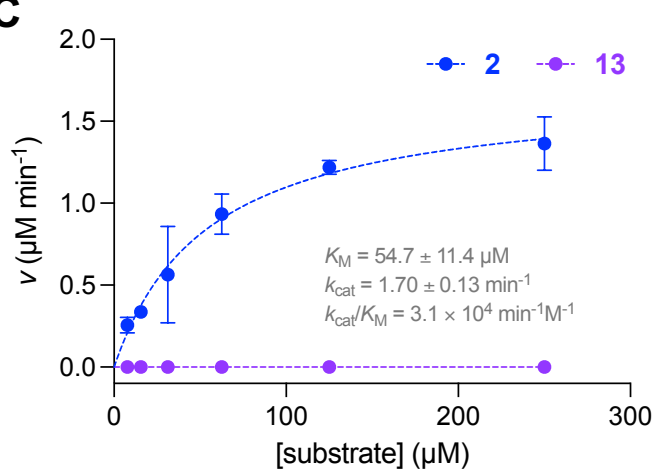

Figure S5. Biochemical characterization of SmbG. (A) SDS-PAGE analysis of SmbG expressed and purified from E. coli. (B) Standard curve of 1. (C) Steady-state kinetic parameters for SmbG. Reactions were performed with $1 \mu \mathrm{M}$ SmbG, $1 \mathrm{mM}$ SAM, and varying concentrations of $\mathbf{2}$ and 13. No $N$-methylation was observed for 13 to give 14. 


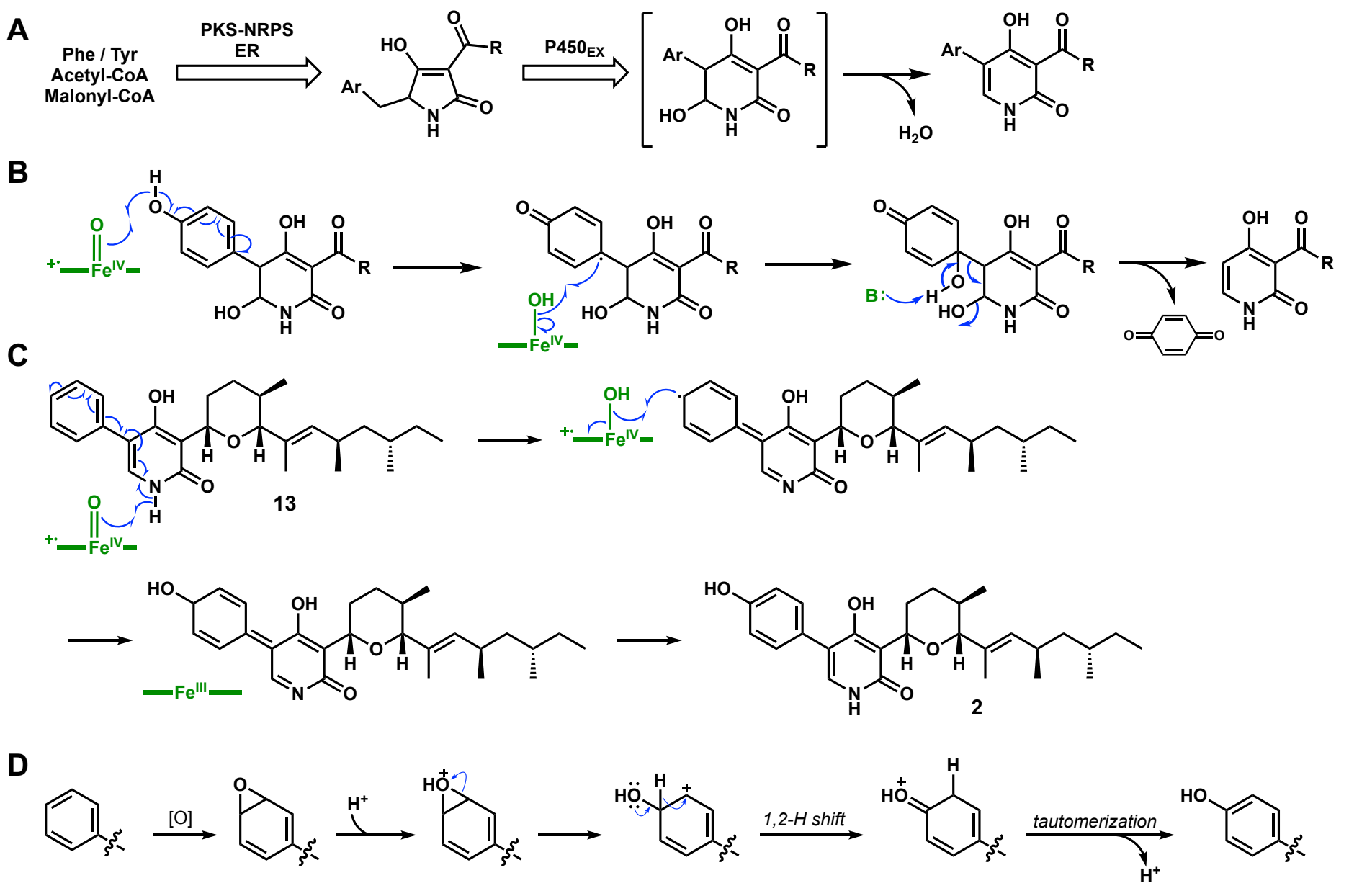

Figure S6. Proposed mechanisms for ring expansion, dephenylation, and aryl hydroxylation. (A) Overview of 2-pyridone biosynthesis by PKS-NRPS, trans-ER, and ring-expansion P450 (P450 $0_{\mathrm{RE}}$ ). (B) Dephenylation has been proposed to be driven by sequential oxygen rebound processes that hydroxylate the 6-C and 1'-C positions, well-poised to release a $p$ benzoquinone that results in the elimination of the 6-OH group to release the dephenylated 2-pyridone alkaloid. ${ }^{8,9}(\mathbf{C})$ Hydroxylation by SmbF may be facilitated by abstraction of hydrogen atom from the amide in the 2-pyridone ring, which generates a radical that can be delocalized to the 4' position of the phenyl group to enable hydroxylation. (D) General mechanism for aryl oxidation via arene oxide. 


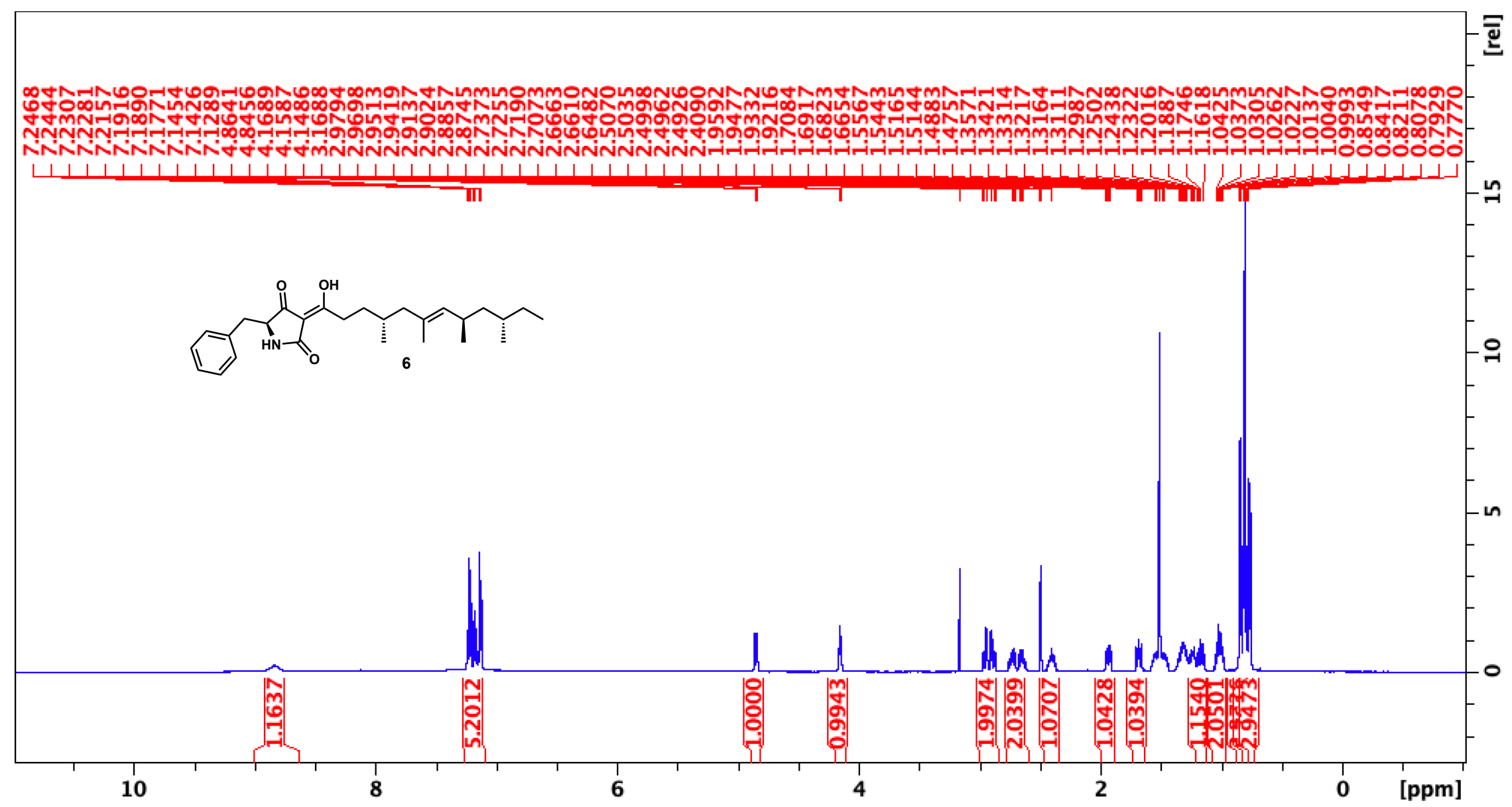

Figure S7. ${ }^{1} \mathrm{H}-\mathrm{NMR}(500 \mathrm{MHz})$ spectrum of compound 6 in DMSO- $d_{6}$. 


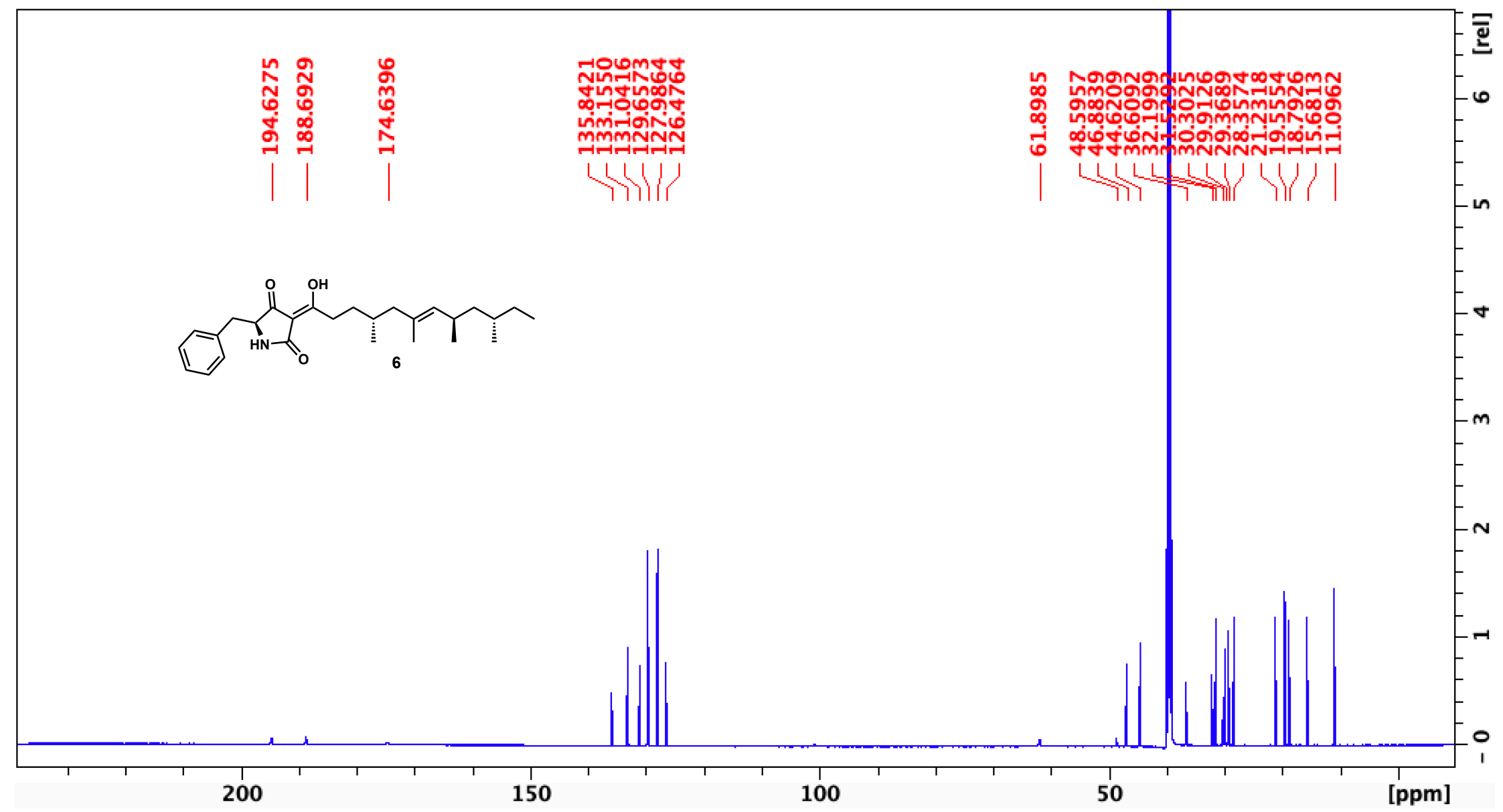

Figure S8. ${ }^{13} \mathrm{C}-\mathrm{NMR}(125 \mathrm{MHz})$ spectrum of compound 6 in DMSO- $d_{6}$. 


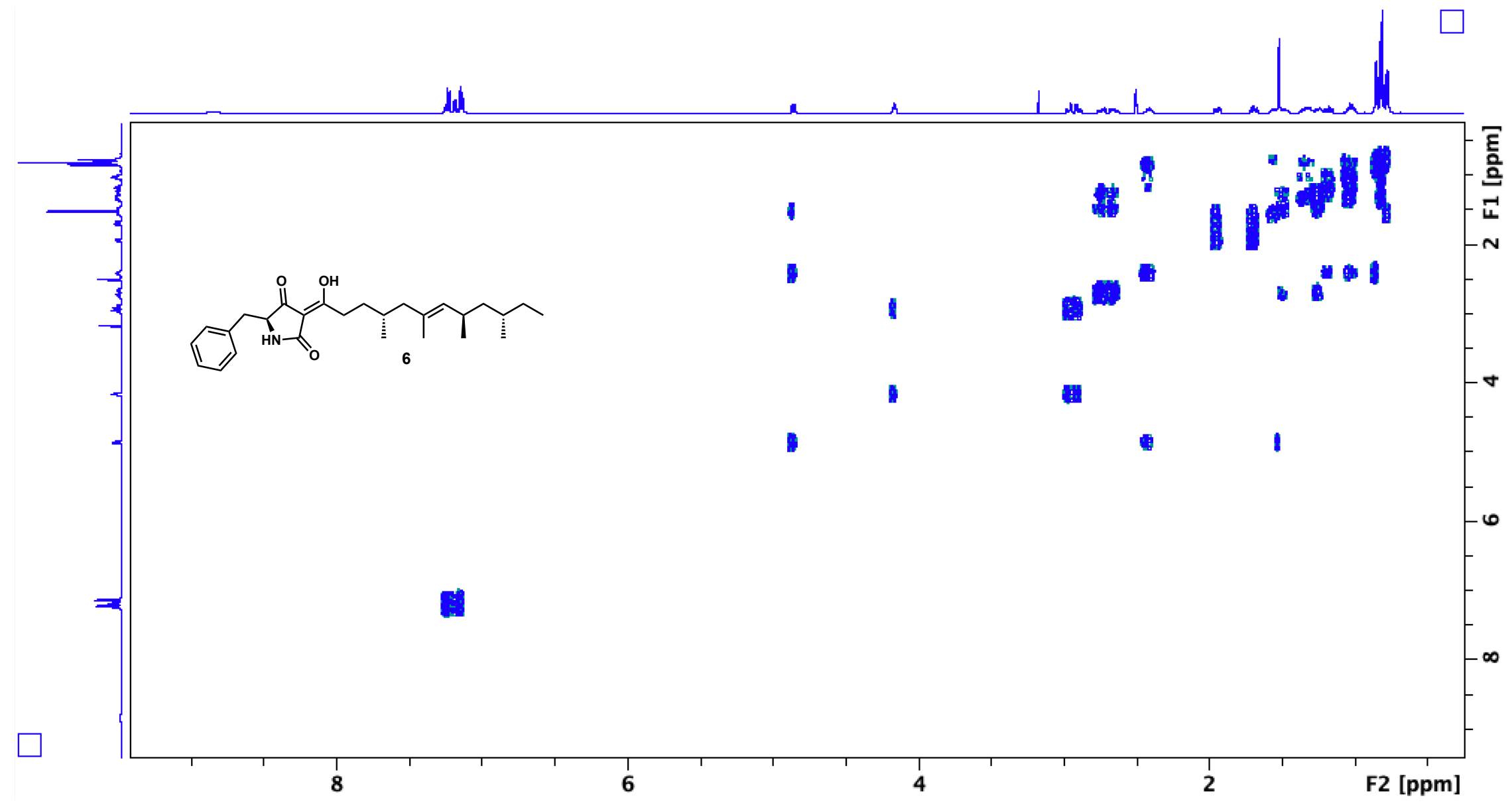

Figure S9. ${ }^{1} \mathrm{H}-{ }^{1} \mathrm{H}$ COSY $(500 \mathrm{MHz})$ spectrum of compound 6 in DMSO- $d_{6}$. 


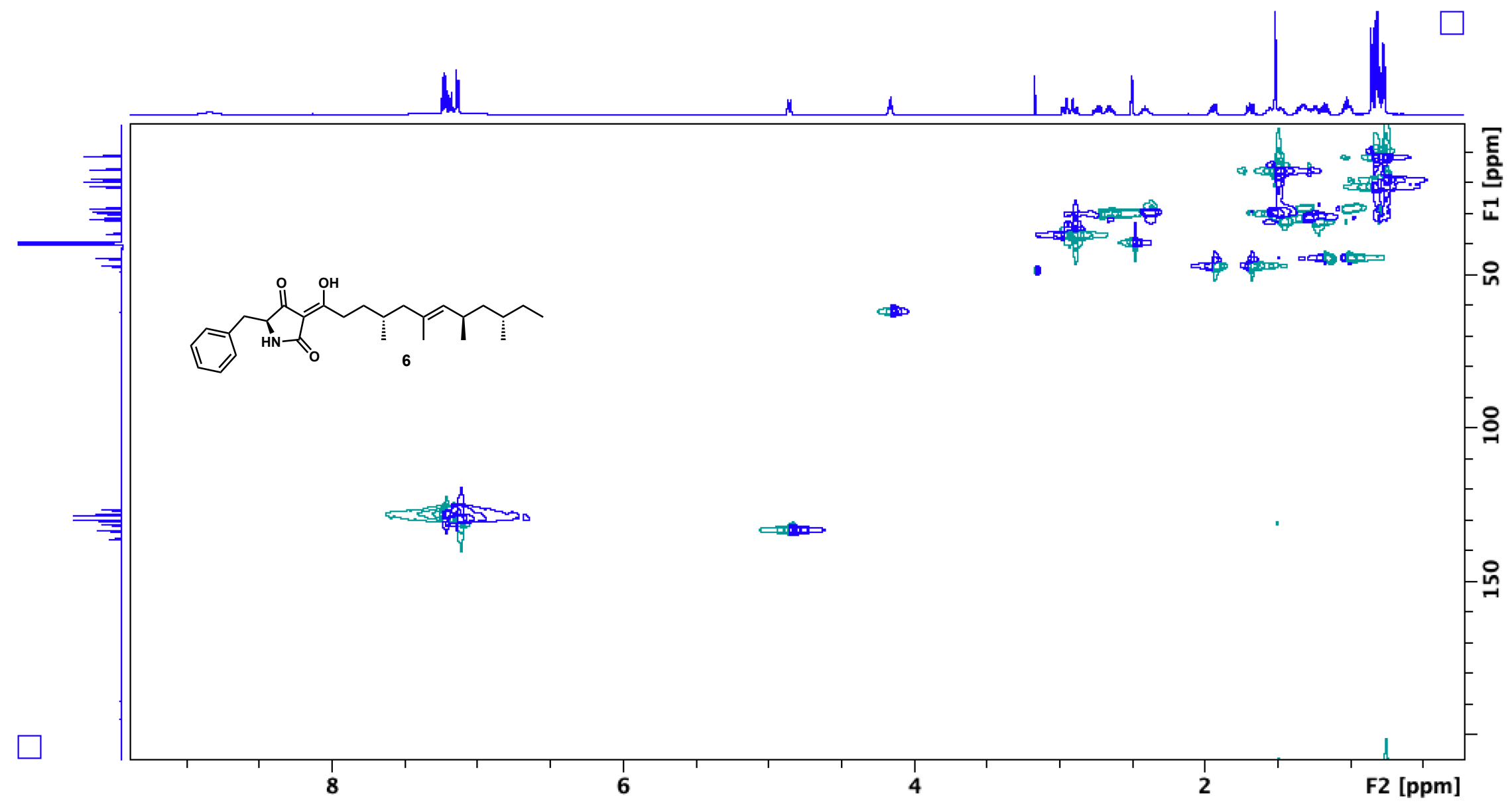

Figure S10. ${ }^{1} \mathrm{H}-{ }^{13} \mathrm{C}$ HSQC spectrum of compound 6 in DMSO- $d_{6}$. 


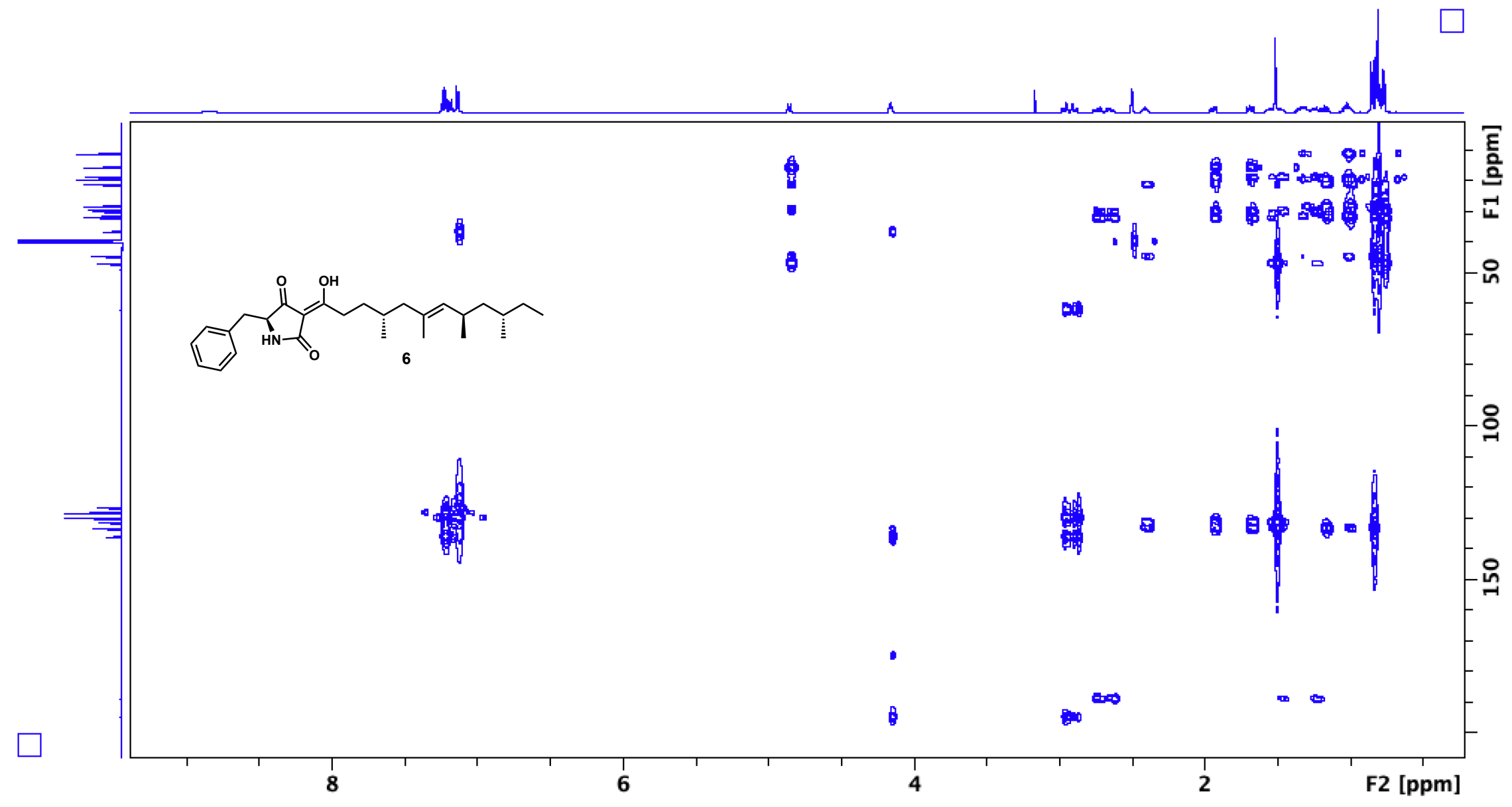

Figure S11. ${ }^{1} \mathrm{H}^{13} \mathrm{C}$ HMBC spectrum of compound 6 in DMSO- $d_{6}$. 


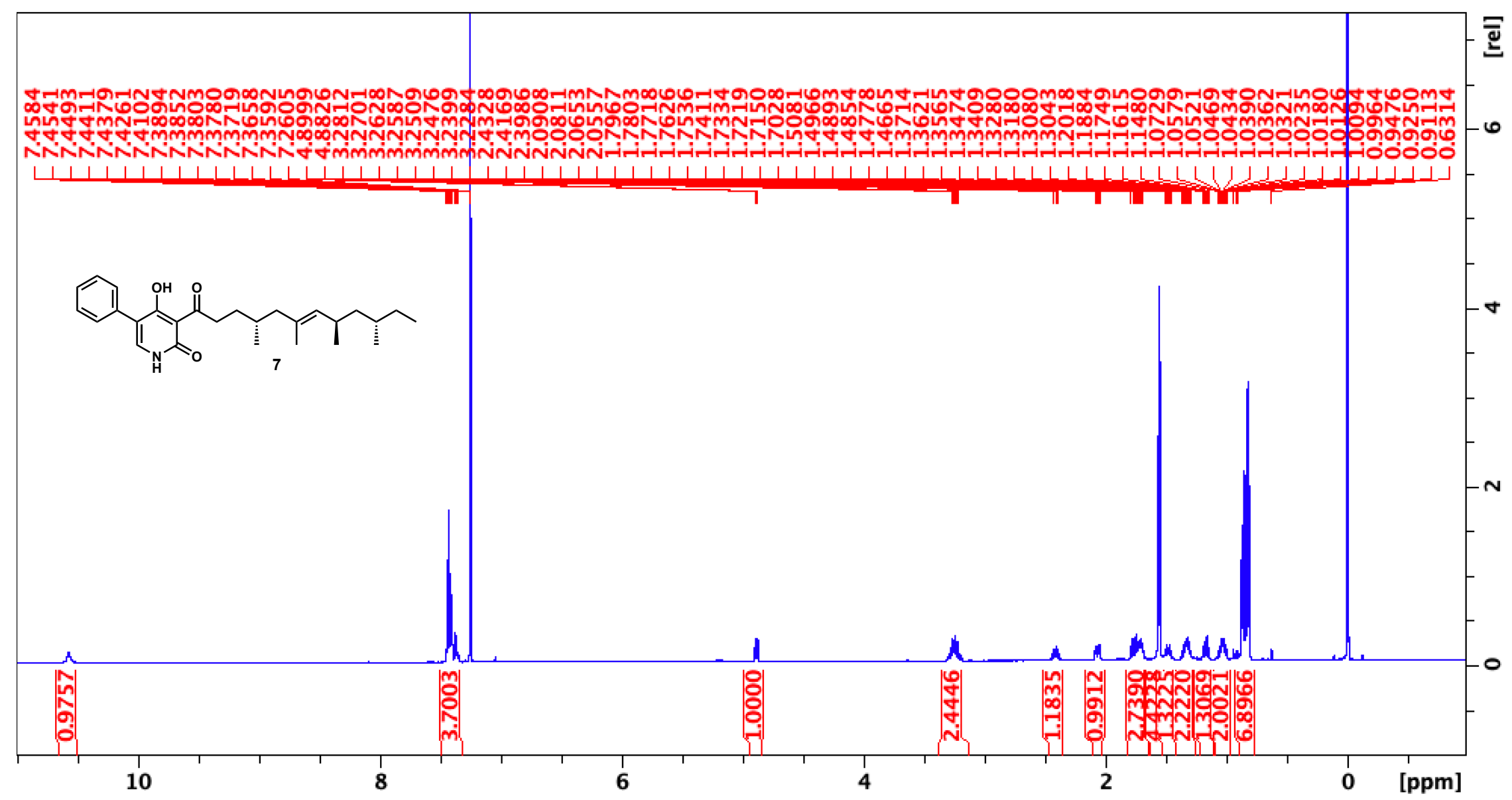

Figure S12. ${ }^{1} \mathrm{H}-\mathrm{NMR}(500 \mathrm{MHz})$ spectrum of compound 7 in $\mathrm{CDCl}_{3}$. 


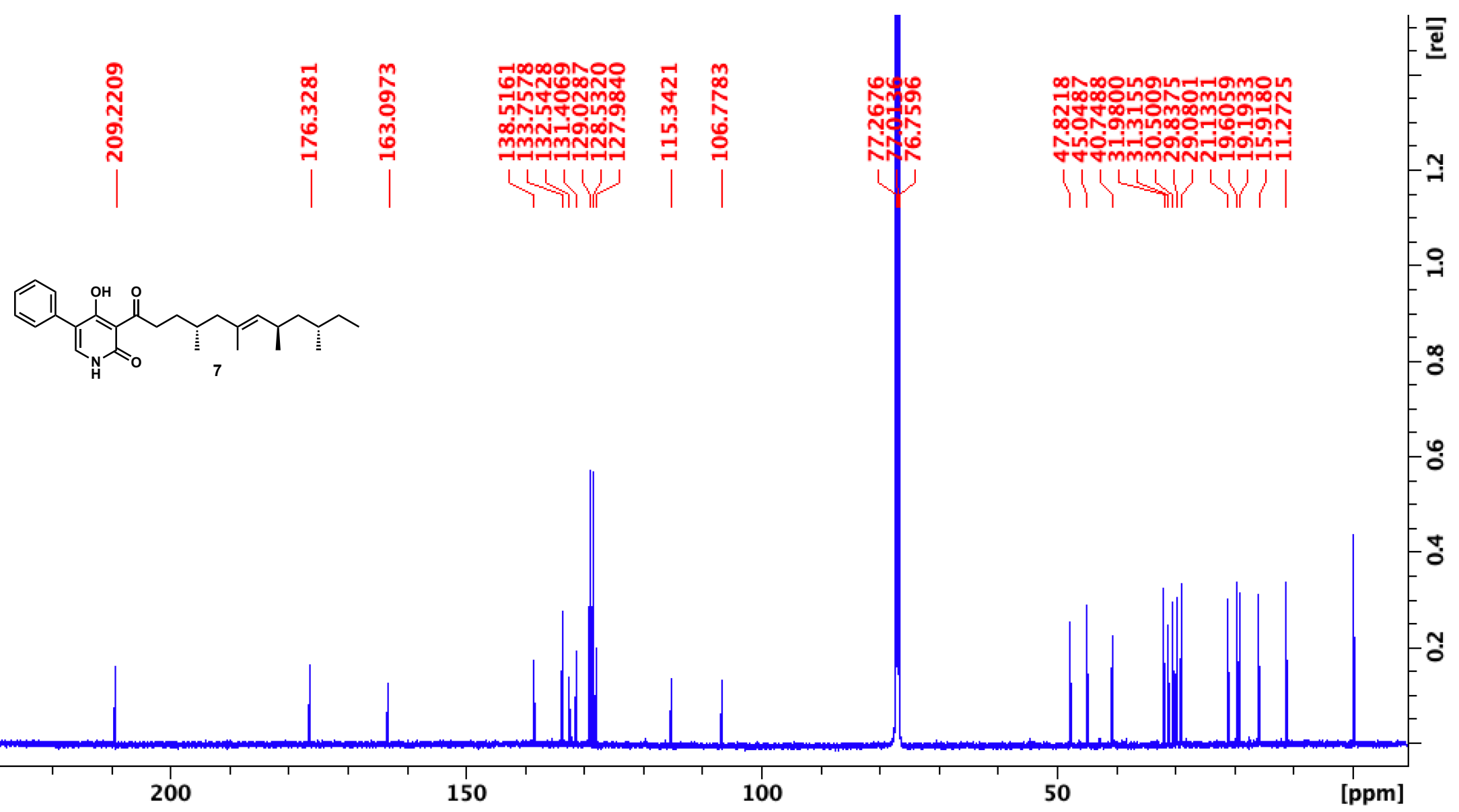

Figure S13. ${ }^{13} \mathrm{C}-\mathrm{NMR}(125 \mathrm{MHz})$ spectrum of compound 7 in $\mathrm{CDCl}_{3}$. 


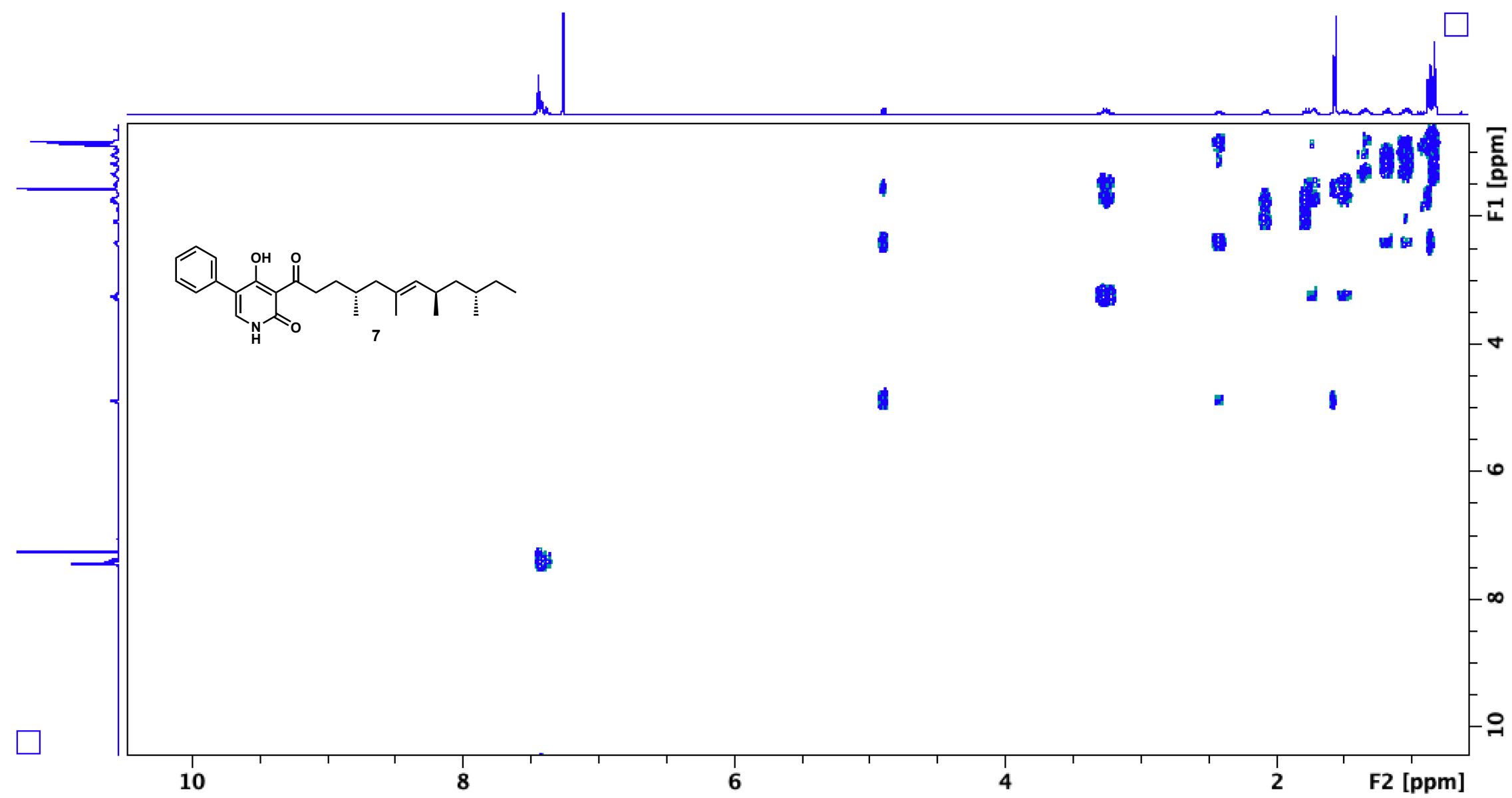

Figure S14. ${ }^{1} \mathrm{H}-{ }^{1} \mathrm{H}$ COSY-NMR spectrum of compound 7 in $\mathrm{CDCl}_{3}$. 


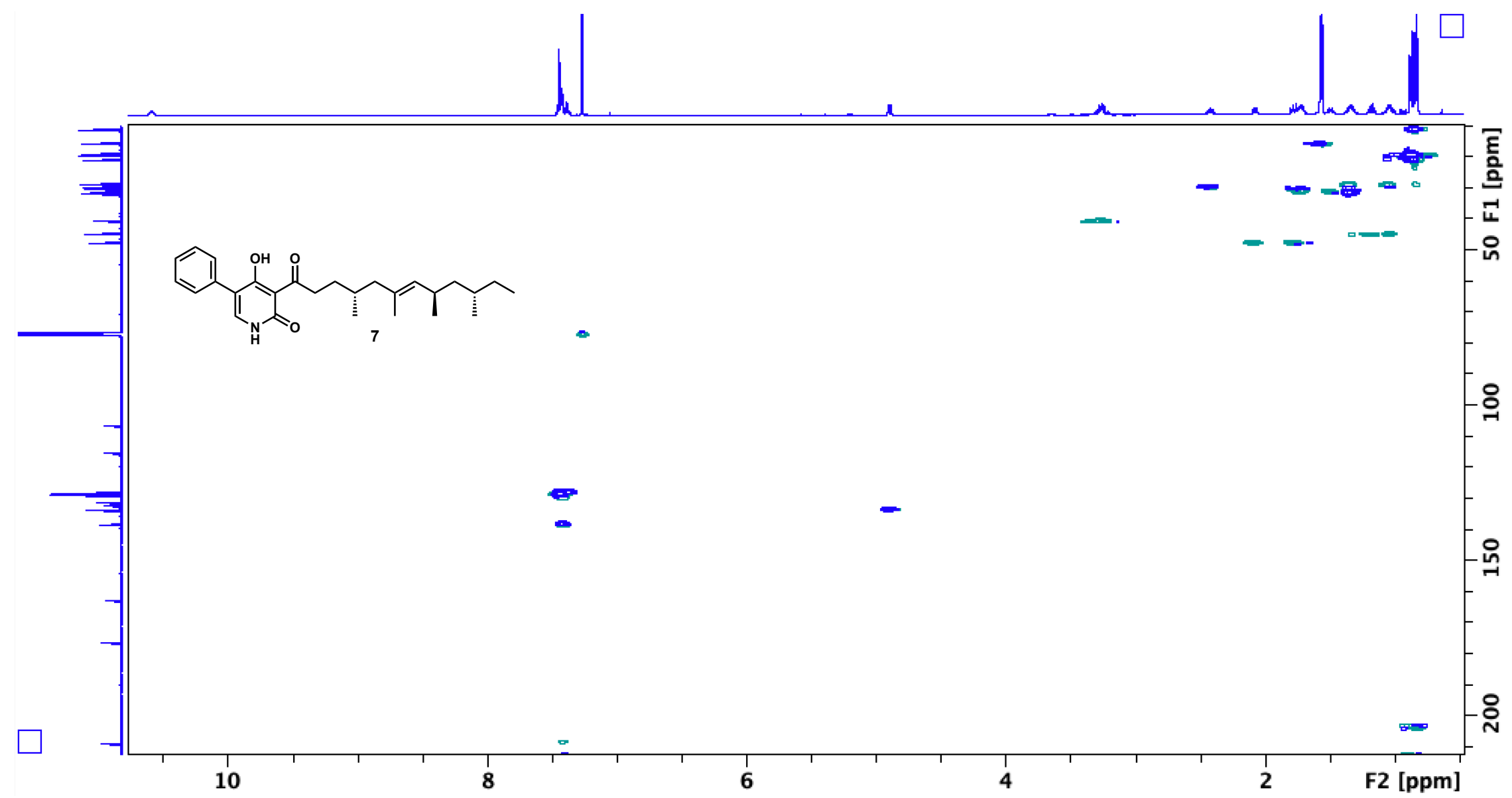

Figure S15. ${ }^{1} \mathrm{H}^{13} \mathrm{C}$ HSQC spectrum of compound 7 in $\mathrm{CDCl}_{3}$. 


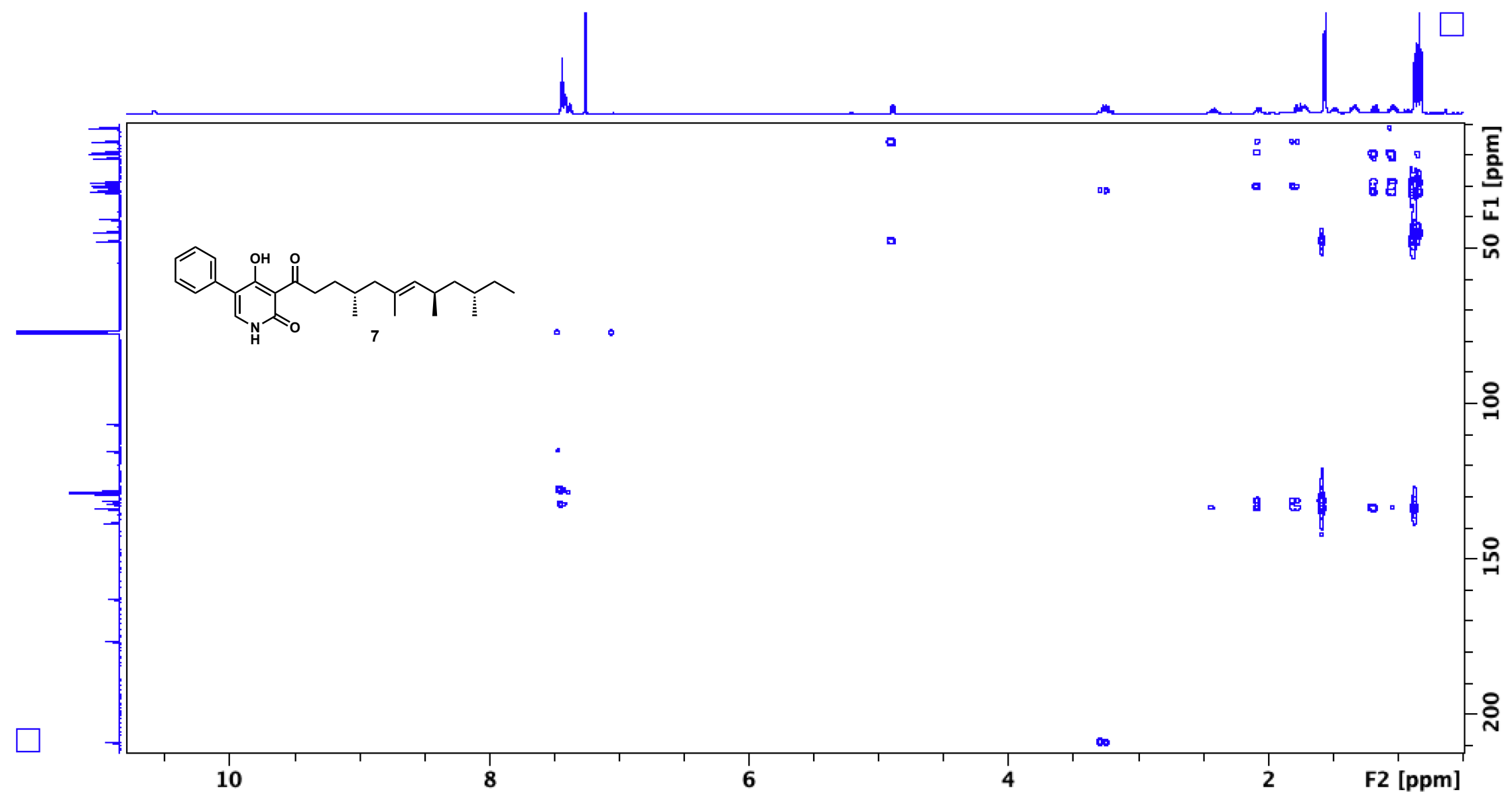

Figure S16. ${ }^{1} \mathrm{H}^{13} \mathrm{C}$ HMBC spectrum of compound 7 in $\mathrm{CDCl}_{3}$. 


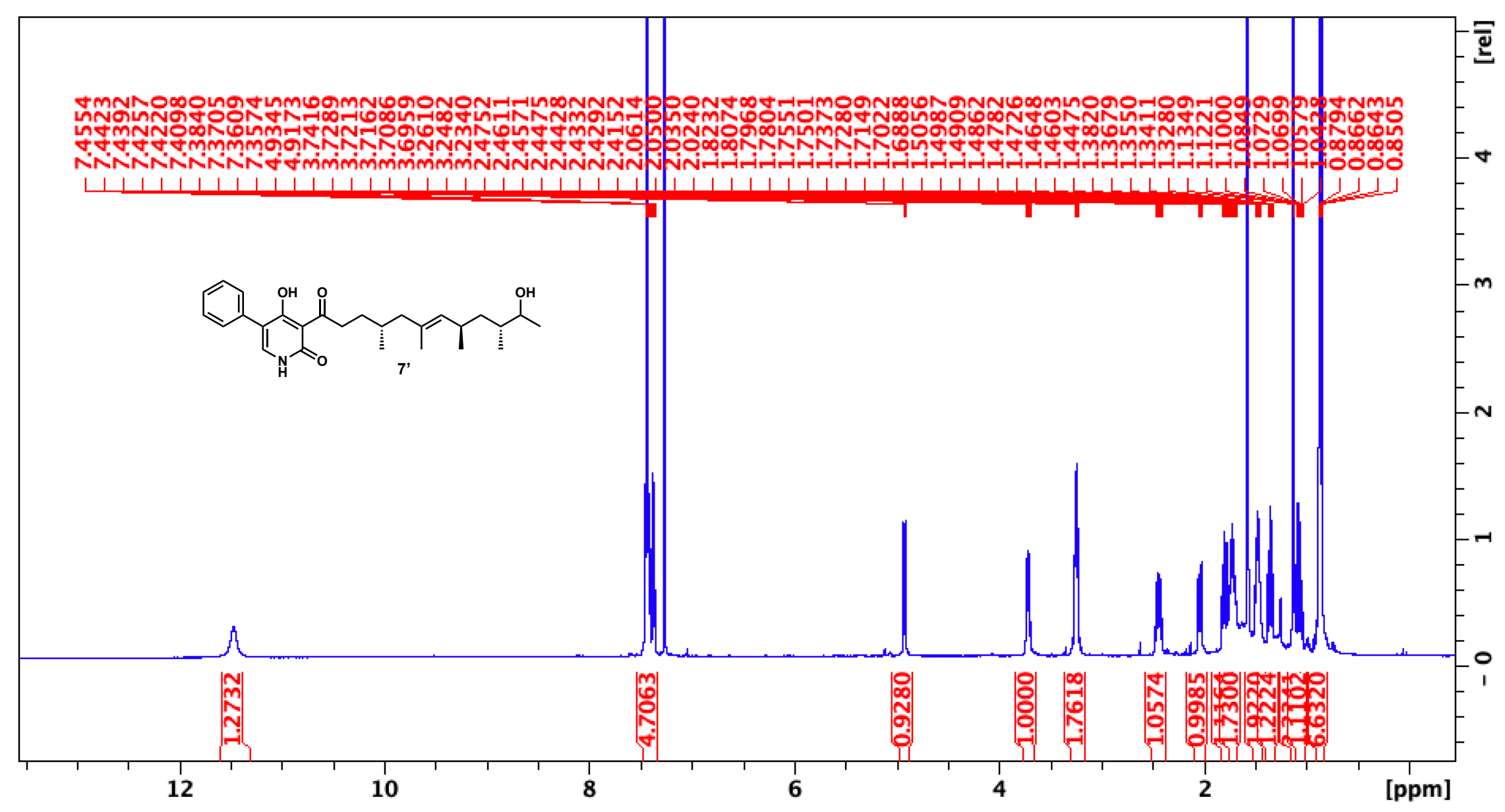

Figure S17. ${ }^{1} \mathrm{H}-\mathrm{NMR}(500 \mathrm{MHz})$ spectrum of compound 7 ' in $\mathrm{CDCl}_{3}$. 


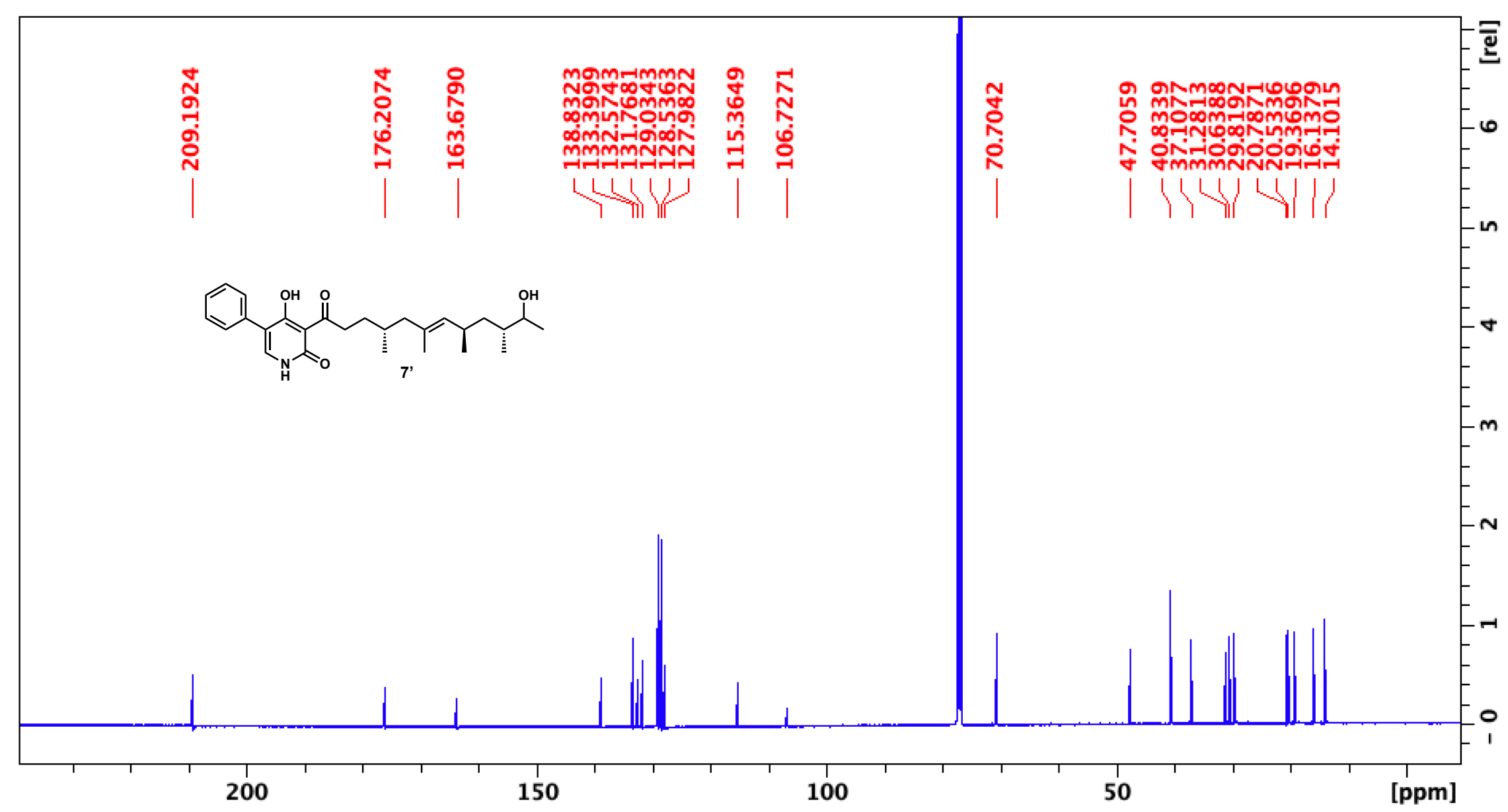

Figure S18. ${ }^{13} \mathrm{C}-\mathrm{NMR}(500 \mathrm{MHz})$ spectrum of compound $7^{\prime}$ in $\mathrm{CDCl}_{3}$. 


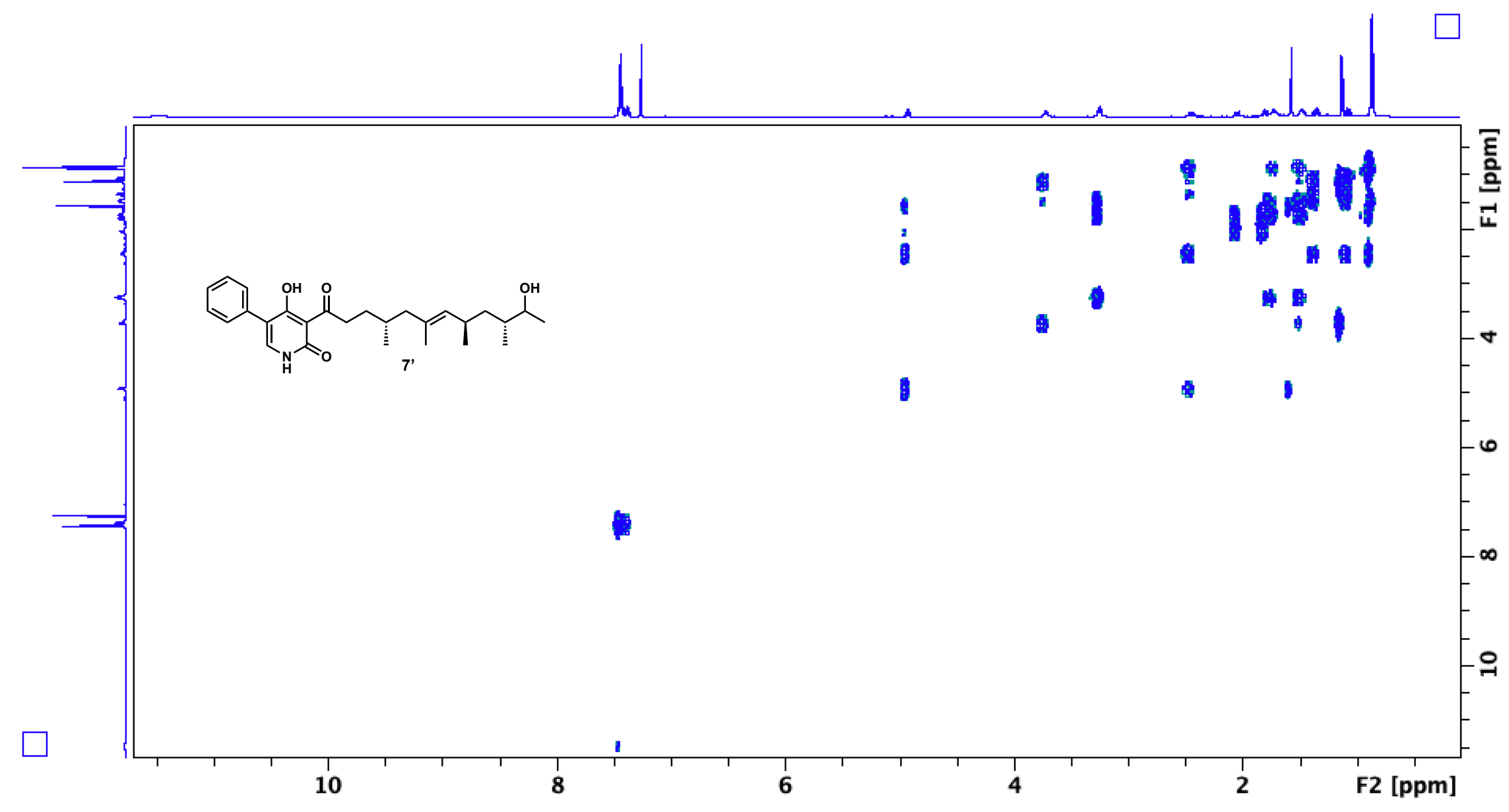

Figure S19. ${ }^{1} \mathrm{H}^{-1} \mathrm{H}$ COSY NMR spectrum of compound 7 ' in $\mathrm{CDCl}_{3}$. 


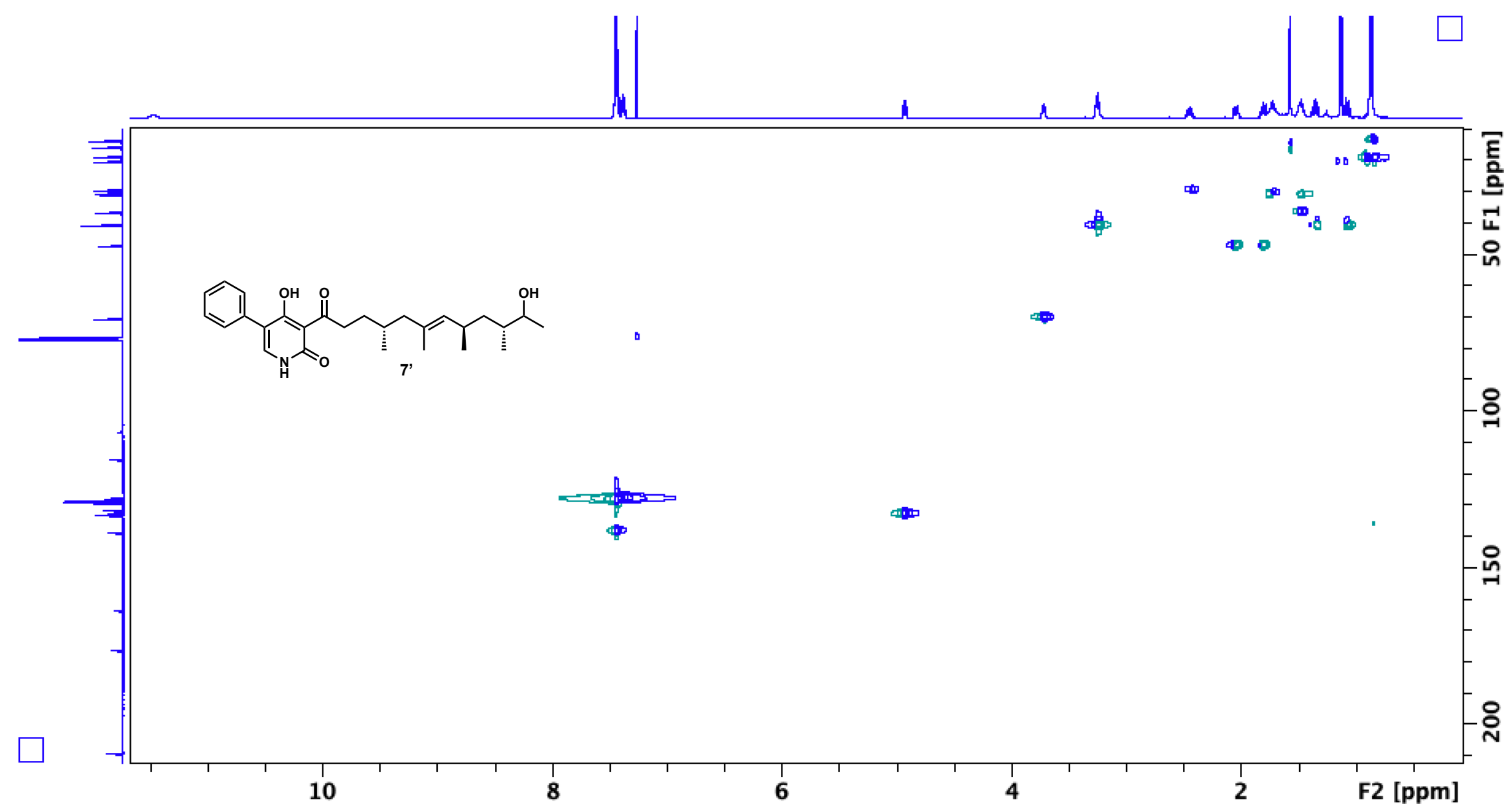

Figure S20. ${ }^{1} \mathrm{H}-{ }^{13} \mathrm{C}$ HSQC spectrum of compound 7 ' in $\mathrm{CDCl}_{3}$. 


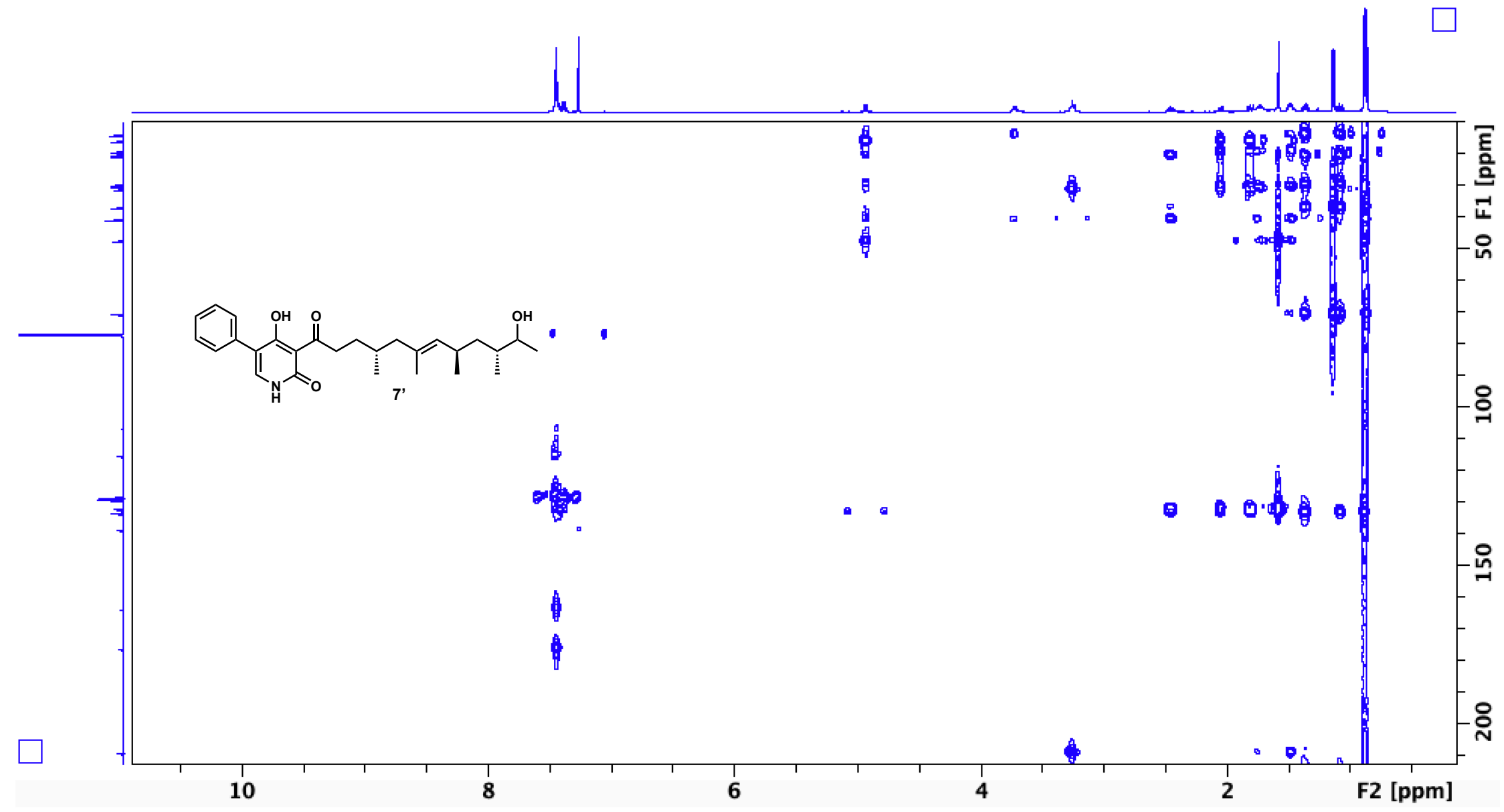

Figure S21. ${ }^{1} \mathrm{H}_{-}{ }^{13} \mathrm{C}$ HMBC spectrum of compound 7 ' in $\mathrm{CDCl}_{3}$. 


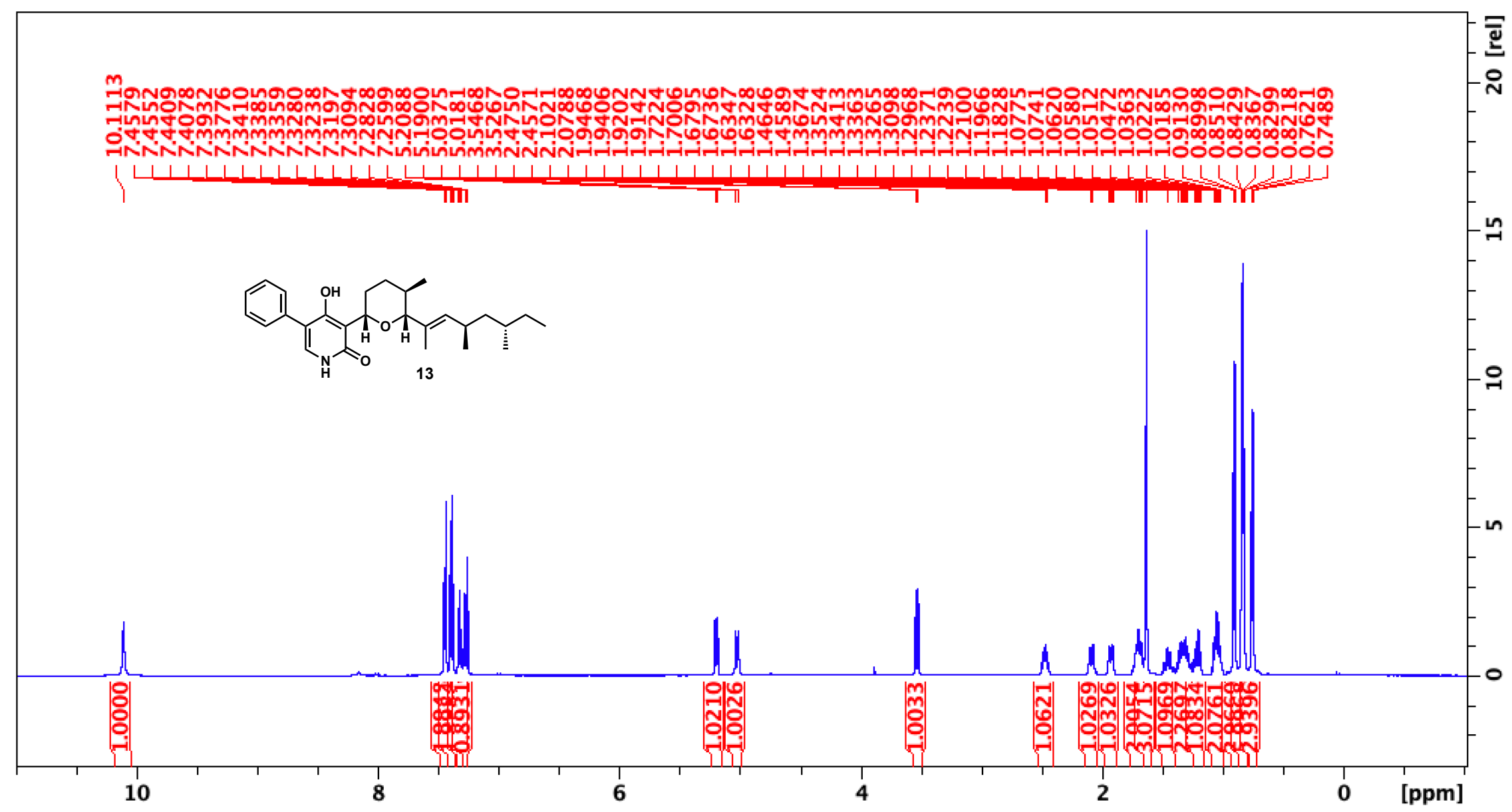

Figure S22. ${ }^{1} \mathrm{H}-\mathrm{NMR}(500 \mathrm{MHz})$ spectrum of compound 13 in $\mathrm{CDCl}_{3}$. 


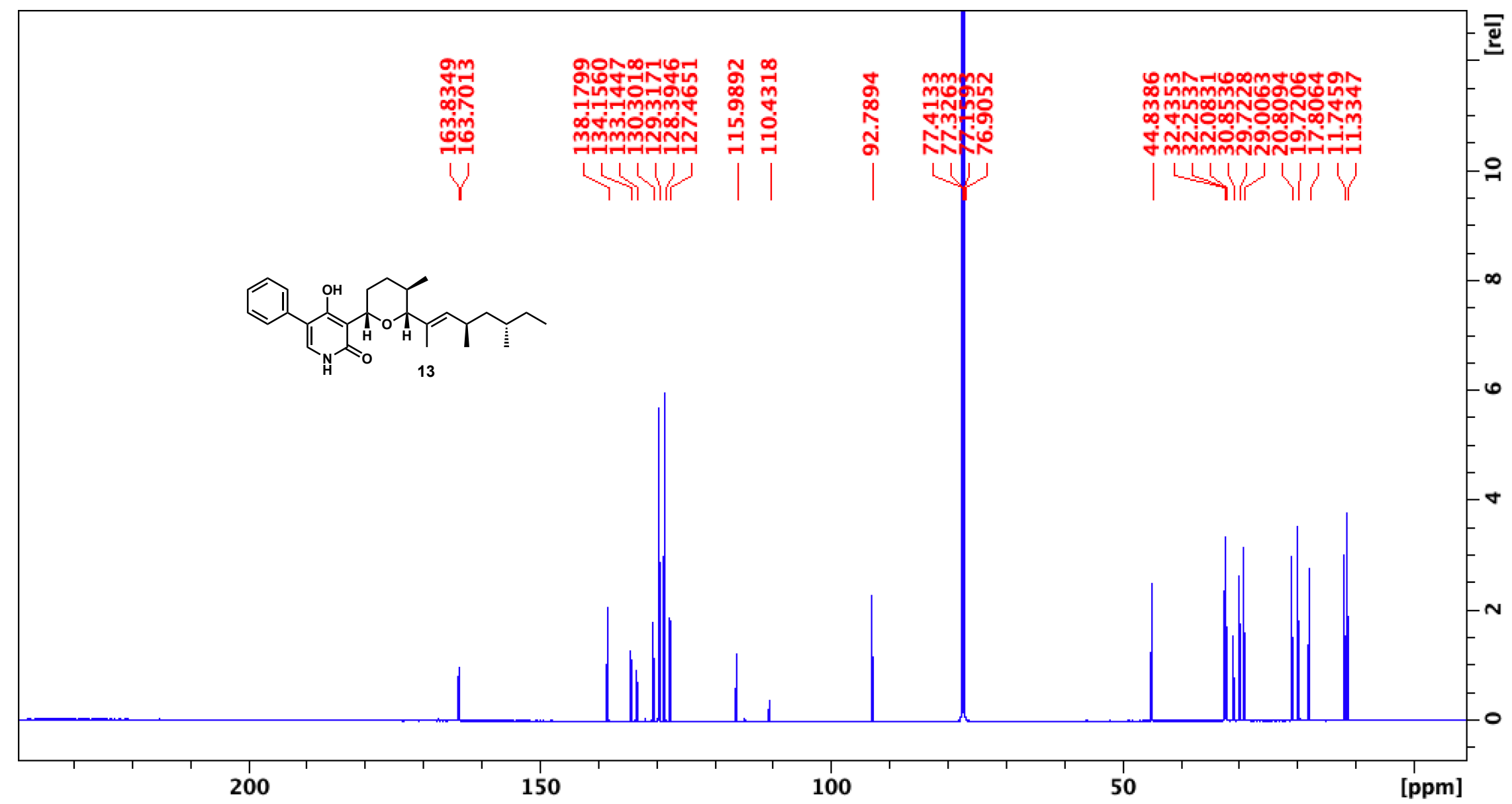

Figure S23. ${ }^{13} \mathrm{C}-\mathrm{NMR}(125 \mathrm{MHz})$ spectrum of compound $\mathbf{1 3}$ in $\mathrm{CDCl}_{3}$. 


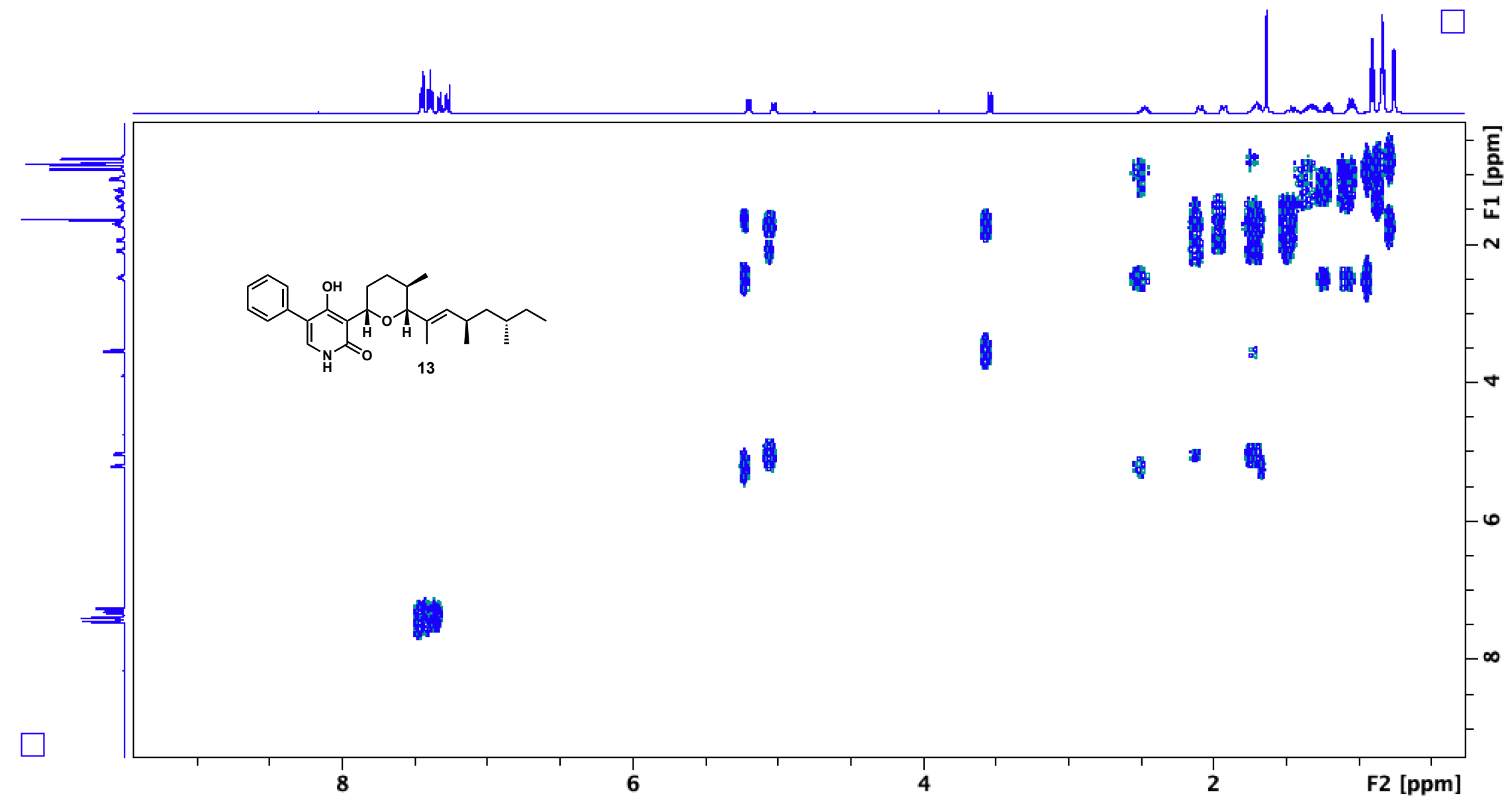

Figure S24. ${ }^{1} \mathrm{H}-{ }^{1} \mathrm{H}$ COSY-NMR spectrum of compound 13 in $\mathrm{CDCl}_{3}$. 


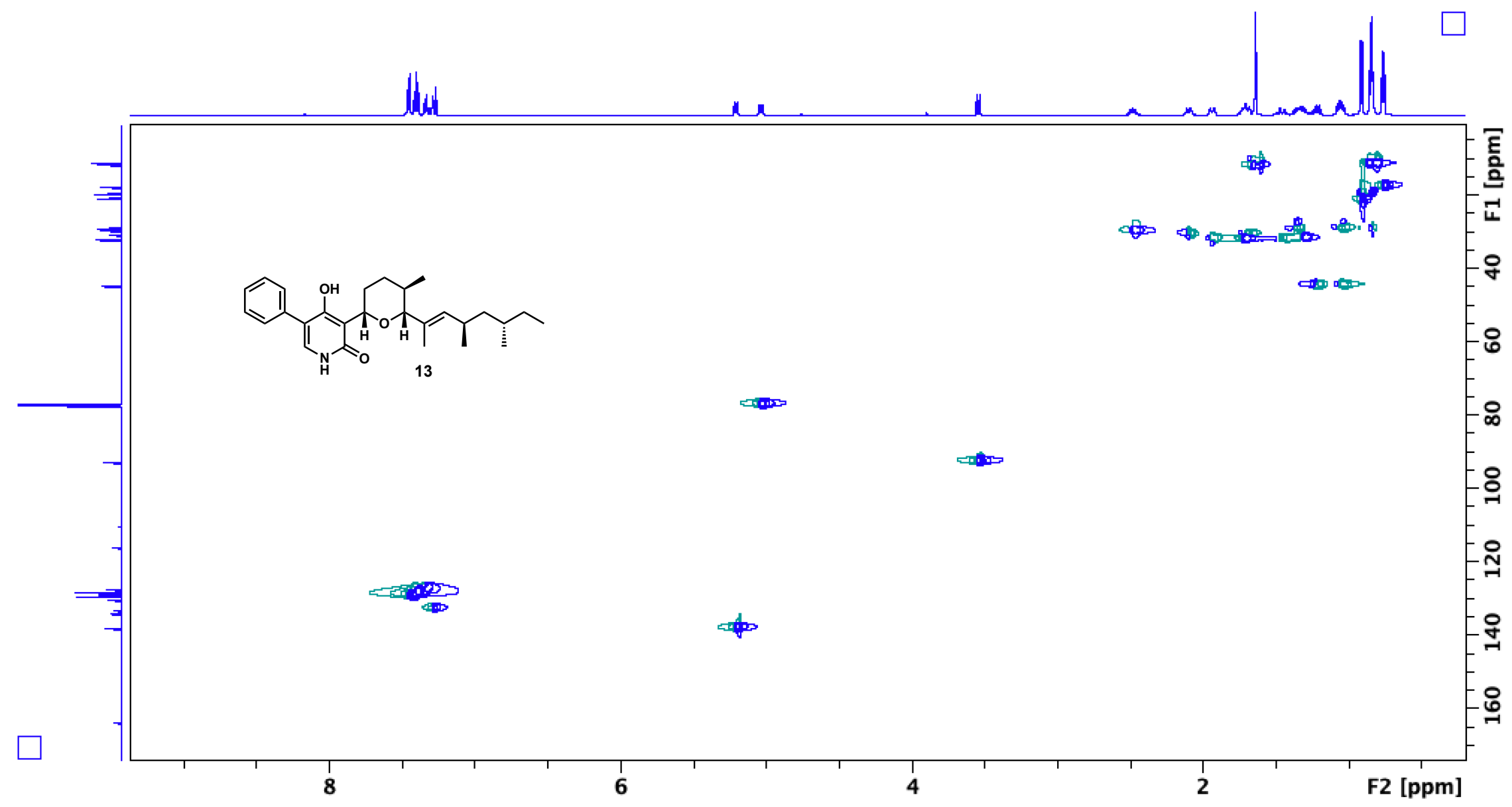

Figure S25. ${ }^{1} \mathrm{H}-{ }^{13} \mathrm{C}$ HSQC spectrum of compound 13 in $\mathrm{CDCl}_{3}$. 


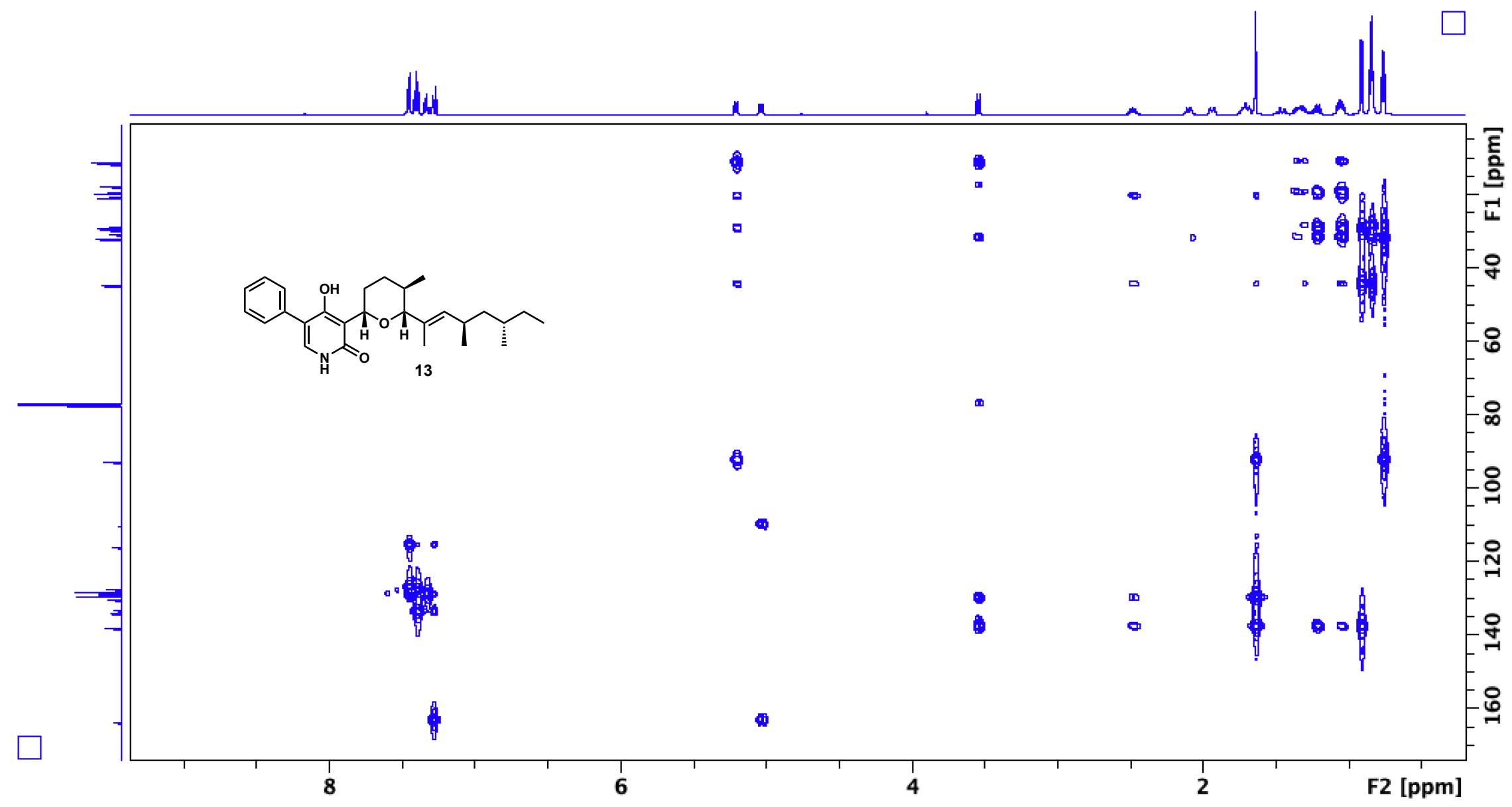

Figure S26. ${ }^{1} \mathrm{H}^{-13} \mathrm{C}$ HMBC spectrum of compound 13 in $\mathrm{CDCl}_{3}$. 


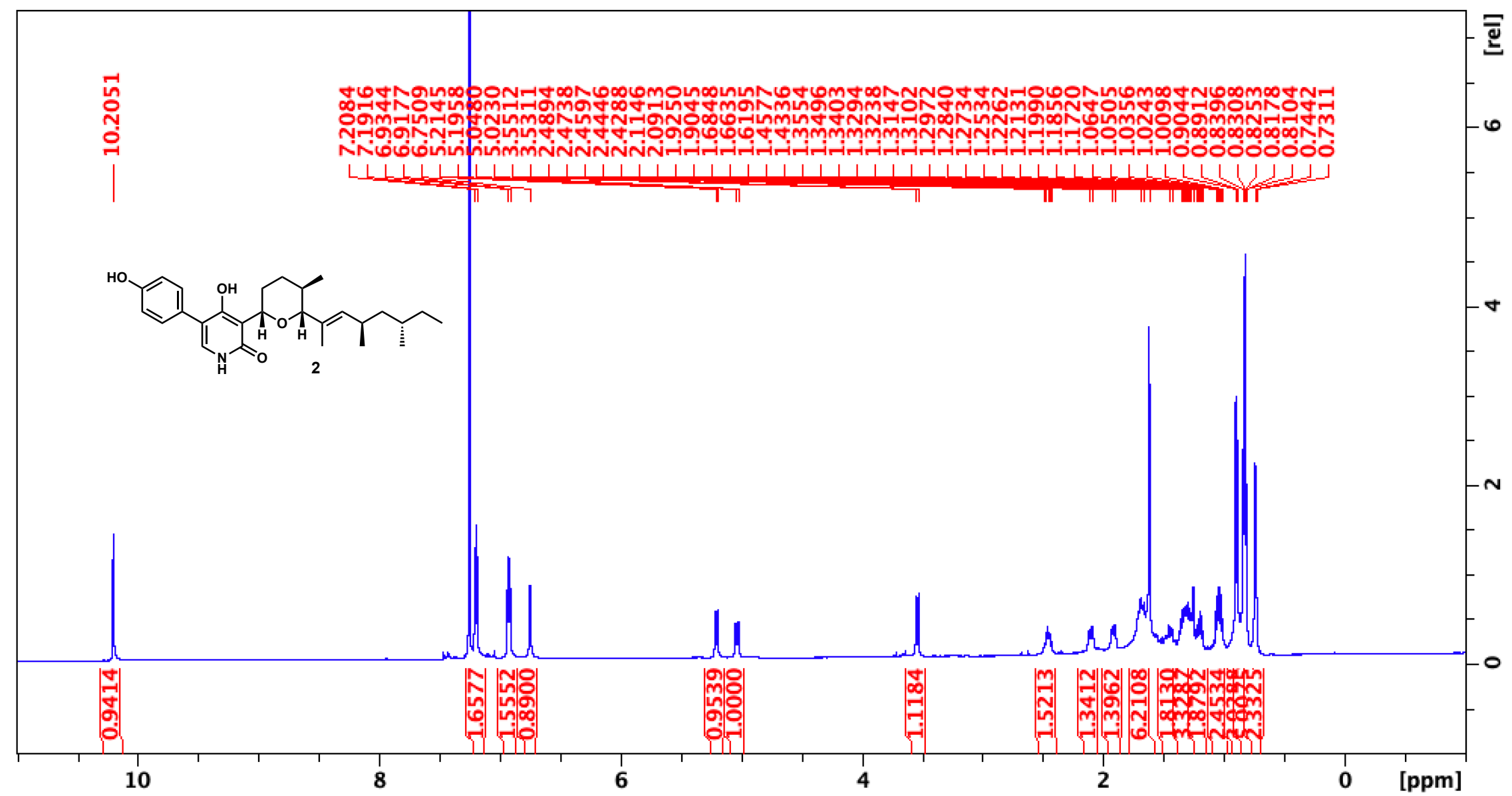

Figure S27. ${ }^{1} \mathrm{H}-\mathrm{NMR}(500 \mathrm{MHz})$ spectrum of compound 2 in $\mathrm{CDCl}_{3}$. 


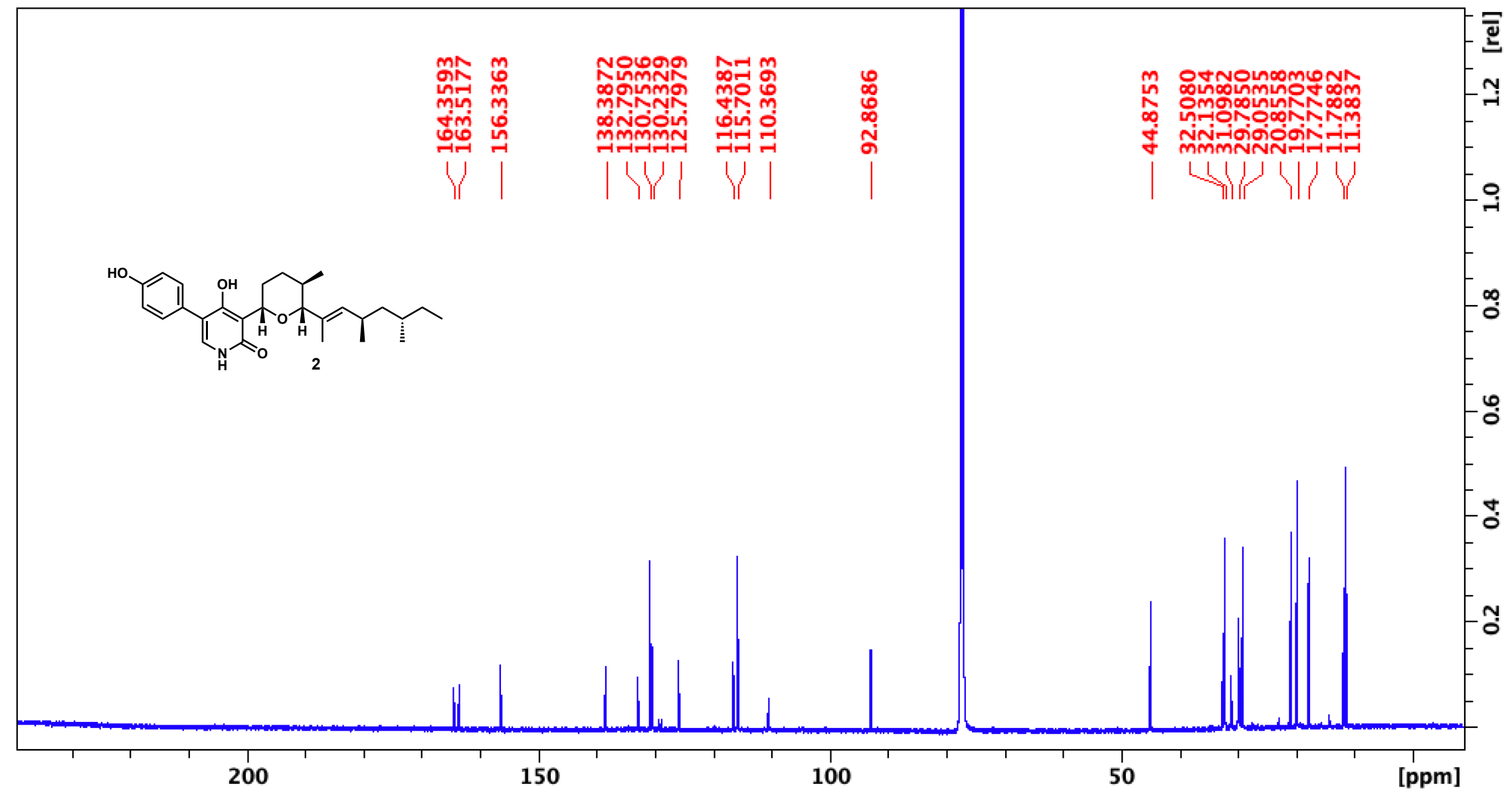

Figure S28. ${ }^{13} \mathrm{C}-\mathrm{NMR}(125 \mathrm{MHz})$ spectrum of compound 2 in $\mathrm{CDCl}_{3}$. 


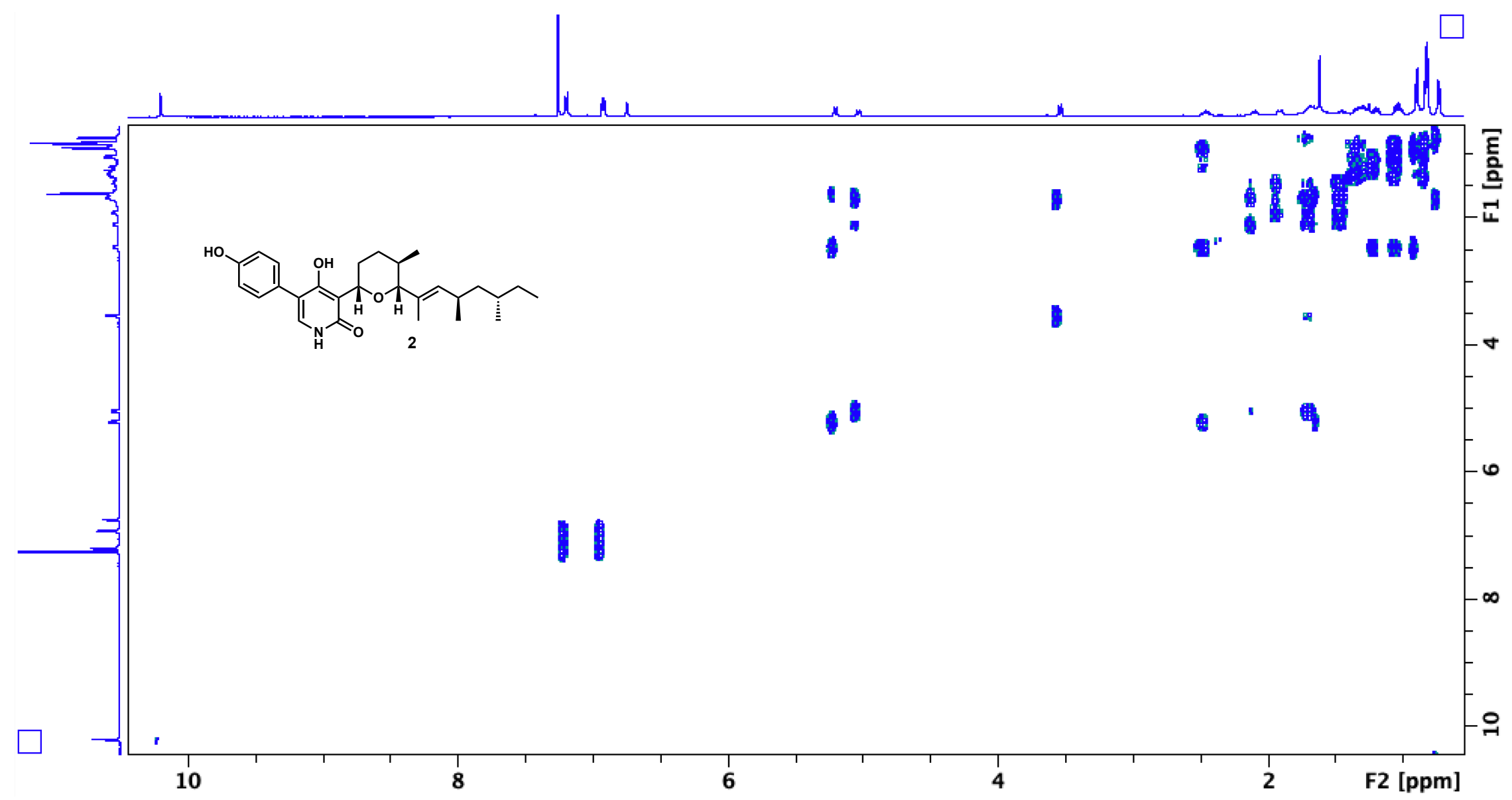

Figure S29. ${ }^{1} \mathrm{H}-{ }^{1} \mathrm{H}$ COSY-NMR spectrum of compound 2 in $\mathrm{CDCl}_{3}$. 


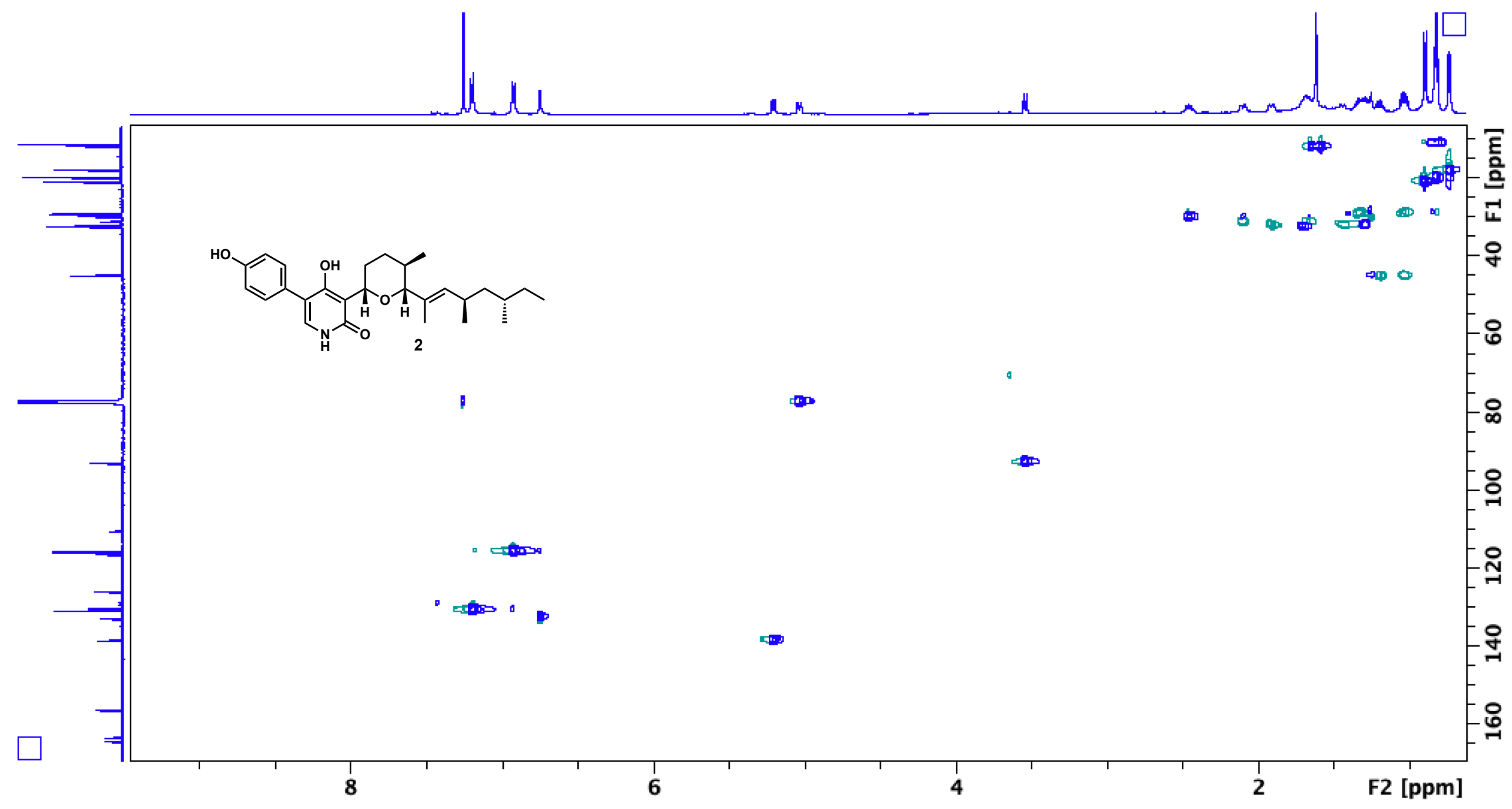

Figure S30. ${ }^{1} \mathrm{H}^{13} \mathrm{C}$ HSQC spectrum of compound 2 in $\mathrm{CDCl}_{3}$. 


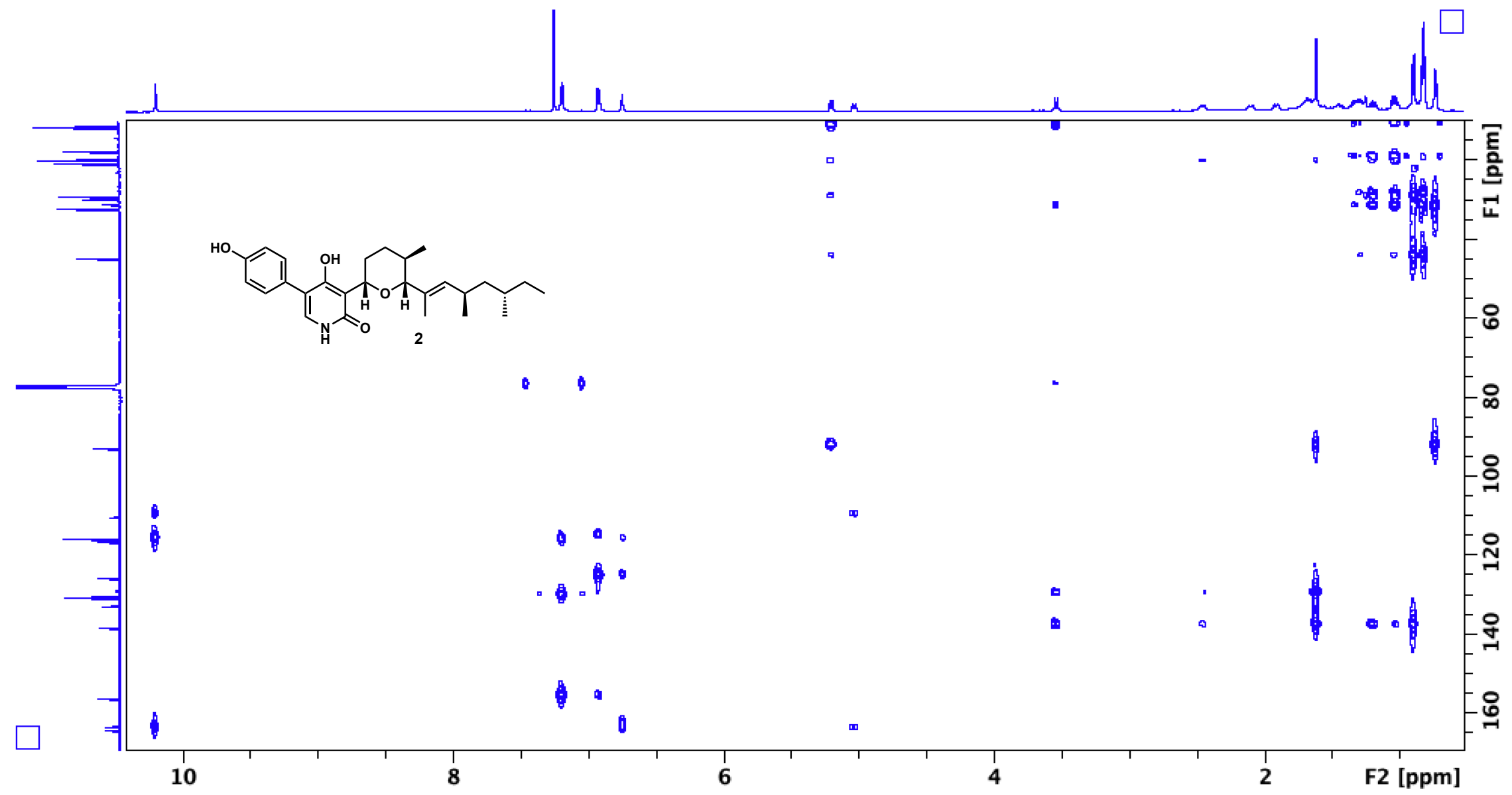

Figure S31. ${ }^{1} \mathrm{H}-{ }^{13} \mathrm{C}$ HMBC spectrum of compound 2 in $\mathrm{CDCl}_{3}$. 


\section{References}

(1) Liu, N.; Hung, Y.-S.; Gao, S.-S.; Hang, L.; Zou, Y.; Chooi, Y.-H.; Tang, Y. Identification and Heterologous Production of a Benzoyl-Primed Tricarboxylic Acid Polyketide Intermediate from the Zaragozic Acid A Biosynthetic Pathway. Org. Lett. 2017, 19 (13), 3560-3563.

(2) Kim, L. J.; Xue, M.; Li, X.; Xu, Z.; Paulson, E.; Mercado, B.; Nelson, H. M.; Herzon, S. B. Structure Revision of the Lomaiviticins. J. Am. Chem. Soc. 2021, 143 (17), 6578-6585.

(3) Sheldrick, G. M. A Short History of SHELX. Acta Crystallogr. A 2008, 64 (1), 112-122.

(4) Sheldrick, G. M. Crystal Structure Refinement with SHELXL. Acta Crystallogr. Sect. C Struct. Chem. 2015, 71 (1), 3-8.

(5) Hübschle, C. B.; Sheldrick, G. M.; Dittrich, B. ShelXle: A Qt Graphical User Interface for SHELXL. J. Appl. Crystallogr. 2011, 44 (6), 1281-1284.

(6) Williams, D. R.; Turske, R. A. Construction of 4-Hydroxy-2-Pyridinones. Total Synthesis of (+)-Sambutoxin. Org. Lett. 2000, 2 (20), 3217-3220.

(7) Nakamura, T.; Harachi, M.; Kano, T.; Mukaeda, Y.; Hosokawa, S. Concise Synthesis of Reduced Propionates by Stereoselective Reductions Combined with the Kobayashi Reaction. Org. Lett. 2013, 15 (12), 3170-3173.

(8) Bat-Erdene, U.; Kanayama, D.; Tan, D.; Turner, W. C.; Houk, K. N.; Ohashi, M.; Tang, Y. Iterative Catalysis in the Biosynthesis of Mitochondrial Complex II Inhibitors Harzianopyridone and Atpenin B. J. Am. Chem. Soc. 2020, 142 (19), 8550-8554.

(9) Ohashi, M.; Jamieson, C. S.; Cai, Y.; Tan, D.; Kanayama, D.; Tang, M.-C.; Anthony, S. M.; Chari, J. V.; Barber, J. S.; Picazo, E.; Kakule, T. B.; Cao, S.; Garg, N. K.; Zhou, J.; Houk, K. N.; Tang, Y. An Enzymatic Alder-Ene Reaction. Nature 2020, 586 (7827), 64-69. . 